\title{
Improved outcome for children and adolescent with acute lymphoblastic leukemia in the first decade of the 21 st century: a report from the Slovak Republic
}

\author{
A. KOLENOVA ${ }^{1, \star}$, E. KAISEROVA ${ }^{1}$, M. MAKOHUSOVA ${ }^{1,4}$, Z. SUBOVA ${ }^{1}$, E. BUBANSKA ${ }^{2}$, I. ORAVKINOVA ${ }^{3}$, P. SVEC ${ }^{1}$, O. FABRI ${ }^{1}$, S. P. HUNGER ${ }^{5}$, \\ S. SUFLIARSKA ${ }^{1}$, S. HORAKOVA ${ }^{1}$, V. MRAZOVA ${ }^{4}$, J. STARY $^{6}$
}

${ }^{1}$ Department of Pediatric Hematology and Oncology, Comenius University - Medical School and University Children's Hospital, Bratislava, Slovak republic; ${ }^{2}$ Department of Pediatric Oncology and Hematology, Children's University Hospital, Banská Bystrica, Slovak republic; ${ }^{3}$ Department of Pediatric Hematology and Oncology, University Children's Hospital Kosice, Slovak Republic; ${ }^{4}$ Department of Chemistry, University of SS. Cyril and Methodius, J. Herdu 2, Trnava,Slovak Republic; ${ }^{5}$ University of Pennsylvania Perelman School of Medicine and The Children's Hospital of Philadelphia, Philadelphia PA USA; ${ }^{6}$ Department of Pediatric Oncology and Hematology, Charles University and University Hospital Motol, Czech Republic

${ }^{\star}$ Correspondence: sasa.kolenova@gmail.com

Received January 24, 2015 / Accepted May 18, 2015

\begin{abstract}
Our aim was to analyze event-free (EFS) and overall survival (OS) among children and adolescents with acute lymphoblastic leukemia (ALL) treated with International BFM Intercontinental trial (ALL IC 2002) therapy in the Slovak Republic. In total, 280 children and adolescent age 1 to 18 years were treated with ALL IC BFM 2002 based therapy from 2002 to 2012, which was divided into two periods. During 2002-2007, when patients were actively enrolled in the ALL IC-BFM 2002 trial, and during 2008-2012 when the trial was closed and patients were treated with the same therapy without randomization. Five-year EFS and OS rates were $79 \%(+/-2.6 \%)$ and $86 \%(+/-2.1 \%)$, respectively, similar to results obtained in the ALL-BFM 95 trial, which was the basis for ALL IC BFM 2002 therapy. The EFS $(p<0.012)$ and OS $(p<0.003)$ were significantly better than the prior Slovak experience in 1997-2001. Survival is improved in standard and intermediate risk groups, including those age 1 to 6 years, and older; with B-cell or T-cell immunophenotype, and is also excellent for those with good early response. The rate of death in induction, cumulative incidence of death in complete remission and of relapse decreased. However, outcome was suboptimal for patients in the high risk group. Current EFS and OS rates for children and adolescents with ALL in the Slovak Republic resembled those obtained in Western Europe as a result of clinical trial participation, and clinical experience acquired with intensive BFM type treatment.
\end{abstract}

Key words: acute lymphoblastic leukemia, children, clinical trial

The treatment of childhood acute lymphoblastic leukemia (ALL) is one of the success stories of clinical oncology [1, 2, 3]. Pediatric ALL 5-year overal survival (OS) rates have improved to approximately $90 \%$ in trials conducted in North America and Western Europe with risk stratification by biological features of leukaemic cells and response to treatment and improved supportive care $[4,5,6,7,8,9,10]$. The outstanding outcome has been obtained in countries with highly developed health care systems and has been possible because of high enrollment in clinical trials by cooperative groups and large institutions, with the two largest being the Children's Oncology Group (COG) based in North America and the
International Berlin-Frankfurt-Munster (BFM) group based in Western Europe [11].

Stary et al have recently reported the results of more than 5,000 children with ALL enrolled in the International BFM Intercontinental trial (ALL IC-BFM 2002) between 2002 and 2007. Fifteen countries participated in the ALL IC-BFM 2002 trial, contributing from 36 to 1,270 patients each [12]. Children with ALL in Slovakia were included in the ALL IC-BFM 2002 trial, which was designed for countries inside the I-BFM study group who had achieved event-free survival (EFS) rates of at least $65 \%$, but were not able to utilize the minimal residual disease (MRD) testing employed in recent BFM trials $[11,12]$. 
In this report, we analyze the outcome of 280 children diagnosed with ALL in Slovakia from 2002 to 2012. During the first part of this period $(2002-2007)$ patients were enrolled in the ALL IC-BFM 2002 trial. After study enrollment was closed, the same therapy was used without randomization (2008-12). Since 2013 Slovakian children with ALL have been enrolled in the new ALL IC BFM 2009 trial.

The ALL IC BFM 2002 prospective randomized international trial provided the first experience for Slovakia to participate in an international pediatric ALL treatment study. Prior to 1992, Slovakian children diagnosed with ALL and other malignancies were treated in several different children's departments using a variety of therapies. Starting in 1992, pediatric cancer therapy in Slovakia was centralized in three children's oncology centers that used the same treatment strategy. The treatment with protocols for ALL initiated in the early 70 's when Čáp, Koza and Černý worked out the first protocols according to American authors Holland and al. [13, 14, 15]. In 1995 the ALL BFM 90 protocol was gradually introduced and since 1997 all three departments of paediatric oncology treated children and adolescents with ALL following the ALL BFM 95 protocol, which formed the basis of the ALL IC-BFM 2002 trial [16].

The objective of this report is to analyze EFS and OS among children and adolescents with ALL treated with ALL IC 2002 therapy in the Slovak Republic between 2002 and 2012, and compare these outcomes to those obtained in 1997-2001 using the same basic therapy without clinical trial participation.

\section{Patients and methods}

Patients. From December 9, 2002 until December 31, 2012, a total of 280 children (age 1-18 years, median 5.7 years) were diagnosed with ALL and treated with ALL IC BFM 2002 therapy at one of 3 Slovak centers in Bratislava $(\mathrm{n}=130 ; 46.4 \%)$, Košice $(\mathrm{n}=90 ; 32.1 \%)$, and Banská Bystrica $(\mathrm{n}=60 ; 21.4 \%)$. Children or their parents gave informed consent to enroll in ALL IC-BFM 2002 (2002-07) or be treated with the same backbone therapy after the trial was closed to enrollment (2008-12). The median follow up period for the analyzed patients was 5.35 years. Because the EFS and OS rates for those enrolled on the trial in 2002-07 $(n=140)$ and those treating with the same regimens in 2008-12 ( $\mathrm{n}=140)$ were very similar, the whole group was pooled to provide more power to examine outcome in patient subgroups (Table I).

Diagnosis. The diagnosis of ALL was based on the French-American-British classification and flow cytometric immunophenotyping using a standard set of monoclonal antibodies according to the European Group for Immunological Characterization of Leukemia [17]. Conventional cytogenetics, fluorescence in situ hybridization (FISH) and reverse transcriptase-polymerase chain reaction (RT-PCR) screening for the ETV6/RUNX1,BCR/ABL1 and MLL/AF4 fusion genes were routinely performed on samples from each patient [18].
Treatment response and relapse criteria. Treatment response was evaluated using cytomorphology, including day 8 prednisone response in peripheral blood, and day 15 and 33 bone marrow $(\mathrm{BM})$ response. Peripheral blood prednisone poor response (PPR) was defined as $\geq 1 \times 10^{9} / \mathrm{L}$ blasts and prednisone good response (PGR) as $<1 \times 10^{9} / \mathrm{L}$ blasts after 7 days of treatment with prednisone and a single dose of intrathecal methotrexate. Bone marrow response was classified as M1 ( $<5 \%$ blasts), M2 ( $\geq 5$ to $<25 \%$ blasts), or M3 ( $\geq 25 \%$ blasts) using standard morphological criteria (12). Complete remission (CR) was defined as less than $5 \%$ blasts in regenerating $\mathrm{BM}$, the absence of leukemic blasts in blood and CSF, and no evidence of extramedullary leukemia. Relapse was defined as recurrence of $\geq 25 \%$ lymphoblasts in the $\mathrm{BM}$ or localized leukemic infiltrates in any site after achieving CR.

Risk stratification and therapy. Risk stratification was performed as described by Stary [12]. Patients with favorable age ( 1 to 6 years), initial white blood cell count $(\mathrm{WBC})<20$ $\mathrm{x} 10^{9} / \mathrm{L}$, and good response on day 8 (PGR), on day 15 (bone marrow M1 or M2) and on day 33 (bone marrow M1) were defined as standard risk (SR). Patients with any one of the following characteristics were defined as high risk (HR): PPR, M3 marrow on day $15, \mathrm{M} 2$ or M3 on day 33, or BCR-ABL1 or MLL-AF4 detected by cytogenetics and/or FISH/RT-PCR. Patients that did not meet SR or HR criteria were defined as intermediate risk (IR).

From 2002-2007, patients were enrolled in the ALL ICBFM 2002 trial and received therapy including randomized interventions as recently published [12, 19]. From 2008-2012, the ALL IC-BFM 2002 trial was closed to enrollment and patients were treated with the same backbone according to the BFM recommendations. The SR and IR patients recieved only a single protocol II block. Patients in the HR group received 6 HR blocks with a single Protocol II reinduction block. Cranial radiotherapy was applied as described by Stary et al. Maintenance therapy continued for all patients until a total treatment duration of 24 months, and consisted of daily oral mercaptopurine and weekly oral methotrexate. Allogeneic SCT was indicated for patients in very HR group who had a matched sibling donor available $[7,17]$.

Statistical analyses. The OS rate was calculated from the date of diagnosis to the date of last follow-up or the date of death. Event-free survival and survival times were calculated from the date of diagnosis to the date of event. Free survival or death events were resistance to therapy (nonresponse), relapse, secondary malignant neoplasm (SMN) or death from any cause. The Kaplan-Meier method was used to estimate survival rates [20]. The Log-Rank test (Mantel-Cox test) was used to compare differences of survival curves [21]. Cumulative incidence curves for relapse and deaths in complete remission were compared with the Gray test [22]. Tests with 0.05 significance level indicated a statistical difference in the survival and cumulative incidence curves between different groups. Analyses were carried out using XLSTAT 2014 and IBM SPSS Statistics 19. 
Table 1. Patient characteristics and treatment results and by risk group for all patients

\begin{tabular}{|c|c|c|c|c|c|c|c|c|c|c|c|}
\hline \multirow[b]{2}{*}{ Variable } & \multicolumn{5}{|c|}{ All } & \multicolumn{2}{|c|}{ SR, \% $(n=82)$} & \multicolumn{2}{|c|}{$\operatorname{MR}, \%(n=161)$} & \multicolumn{2}{|c|}{ HR, \% $(n=37)$} \\
\hline & & $\mathbf{n}$ & $\%$ & Events, $\mathbf{n}$ & 5-y EFS (SE) & $\mathbf{n}$ & $\%$ & $\mathbf{n}$ & $\%$ & $\mathbf{n}$ & $\%$ \\
\hline \multirow{3}{*}{ Sex } & All & 280 & 100.0 & 58 & $0.788(0.026)$ & 82 & 100.0 & 161 & 100.0 & 37 & 100.0 \\
\hline & Male & 185 & 66.1 & 39 & $0.784(0.032)$ & 57 & 69.5 & 99 & 61.5 & 29 & 78.4 \\
\hline & Female & 95 & 33.9 & 19 & $0.794(0.044)$ & 25 & 30.5 & 62 & 38.5 & 8 & 21.6 \\
\hline \multirow[t]{3}{*}{$\operatorname{Age}^{b}$} & 1 to less than $6 y$ & 145 & 51.8 & 21 & $0.857(0.031)$ & 82 & 100.0 & 55 & 34.2 & 8 & 21.6 \\
\hline & 6 to less than $10 y$ & 52 & 18.6 & 8 & $0.822(0.058)$ & 0 & 0.0 & 44 & 27.3 & 8 & 21.6 \\
\hline & $10 \mathrm{y}$ and older & 83 & 29.6 & 29 & $0.647(0.054)$ & 0 & 0.0 & 62 & 38.5 & 21 & 56.8 \\
\hline \multirow[t]{3}{*}{ Initial WBC $(/ \mu \mathrm{L})^{\mathrm{a}}$} & Less than 20000 & 172 & 61.4 & 33 & $0.808(0.032)$ & 82 & 100.0 & 77 & 47.8 & 13 & 35.1 \\
\hline & 20000 to less than $100 \times 10^{9} / \mathrm{L}$ & 72 & 25.7 & 13 & $0.845(0.043)$ & 0 & 0.0 & 66 & 41.0 & 6 & 16.2 \\
\hline & 100000 and over & 36 & 12.9 & 12 & $0.663(0.080)$ & 0 & 0.0 & 18 & 11.2 & 18 & 48.6 \\
\hline \multirow[t]{3}{*}{ CNS status $^{b}$} & $\mathrm{CNS} 1$ & 203 & 72.5 & 38 & $0.810(0.029)$ & 61 & 74.4 & 123 & 76.4 & 19 & 51.4 \\
\hline & CNS2 & 57 & 20.4 & 11 & $0.805(0.053)$ & 20 & 24.4 & 28 & 17.4 & 9 & 24.3 \\
\hline & CNS3 & 20 & 7.1 & 9 & $0.495(0.124)$ & 1 & 1.2 & 10 & 6.2 & 9 & 24.3 \\
\hline \multirow[t]{2}{*}{ Precursor } & Precursor T & 42 & 15.0 & 10 & $0.760(0.066)$ & 1 & 1.2 & 24 & 14.9 & 17 & 45.9 \\
\hline & Precursor B & 238 & 85.0 & 48 & $0.793(0.028)$ & 81 & 98.8 & 137 & 85.1 & 20 & 54.1 \\
\hline \multirow[t]{3}{*}{ ETV6/RUNX 1} & Negative & 223 & 79.6 & 46 & $0.792(0.029)$ & 65 & 79.3 & 123 & 76.4 & 35 & 94.6 \\
\hline & Positive & 46 & 16.4 & 8 & $0.811(0.061)$ & 16 & 19.5 & 29 & 18.0 & 1 & 2.7 \\
\hline & No data & 11 & 3.9 & 4 & $0.582(0.169)$ & 1 & 1.2 & 9 & 5.6 & 1 & 2.7 \\
\hline \multirow[t]{3}{*}{ BCR/ABL } & Negative & 262 & 93.6 & 49 & $0.808(0.026)$ & 79 & 96.3 & 152 & 94.4 & 31 & 83.8 \\
\hline & Positive & 5 & 1.8 & 5 & $0.000(0.000)$ & 0 & 0.0 & 0 & 0.0 & 5 & 13.5 \\
\hline & No data & 13 & 4.6 & 4 & $0.692(0.128)$ & 3 & 3.7 & 9 & 5.6 & 1 & 2.7 \\
\hline \multirow[t]{3}{*}{ MLL/AF4 } & Negative & 266 & 95.0 & 54 & $0.792(0.026)$ & 79 & 96.3 & 153 & 95.0 & 34 & 91.9 \\
\hline & Positive & 4 & 1.4 & 0 & $1.000(0.000)$ & 1 & 1.2 & 1 & 0.6 & 2 & 5.4 \\
\hline & No data & 10 & 3.6 & 4 & $0.600(0.155)$ & 2 & 2.4 & 7 & 4.3 & 1 & 2.7 \\
\hline \multirow[t]{3}{*}{ Hyperdiploidy } & Negative & 250 & 89.3 & 53 & $0.785(0.027)$ & 70 & 85.4 & 145 & 90.1 & 35 & 94.6 \\
\hline & Positive & 26 & 9.3 & 4 & $0.826(0.080)$ & 11 & 13.4 & 14 & 8.7 & 1 & 2.7 \\
\hline & No data & 3 & 1.1 & 0 & $0.000(0.000)$ & 1 & 1.2 & 2 & 1.2 & 0 & 0.0 \\
\hline \multirow{2}{*}{$\begin{array}{l}\text { T lineage NCI risk } \\
\text { criteria }\end{array}$} & Standard risk & 8 & 2.9 & 1 & $0.875(0.117)$ & 1 & 1.2 & 6 & 3.7 & 1 & 2.7 \\
\hline & High risk & 34 & 12.1 & 9 & $0.733(0.076)$ & 0 & 0.0 & 18 & 11.2 & 16 & 43.2 \\
\hline \multirow{2}{*}{$\begin{array}{l}\text { Non-T lineage NCI } \\
\text { risk criteria }\end{array}$} & Standard risk & 149 & 53.2 & 20 & $0.865(0.030)$ & 81 & 98.8 & 63 & 39.1 & 5 & 13.5 \\
\hline & High risk & 89 & 31.8 & 28 & $0.678(0.051)$ & 0 & 0.0 & 74 & 46.0 & 15 & 40.5 \\
\hline \multirow[t]{2}{*}{ Prednisone response $^{b}$} & Good & 257 & 91.8 & 49 & $0.806(0.026)$ & 82 & 100.0 & 161 & 100.0 & 14 & 37.8 \\
\hline & Poor & 23 & 8.2 & 9 & $0.598(0.105)$ & 0 & 0.0 & 0 & 0.0 & 23 & 62.2 \\
\hline \multirow[t]{3}{*}{$\mathrm{BM}$ day $15^{\mathrm{b}}$} & M1 & 193 & 68.9 & 25 & $0.868(0.026)$ & 69 & 84.1 & 121 & 75.2 & 3 & 8.1 \\
\hline & M2 & 66 & 23.6 & 19 & 0.709 (0.059) & 13 & 15.9 & 40 & 24.8 & 13 & 35.1 \\
\hline & M3 & 21 & 7.5 & 14 & $0.291(0.108)$ & 0 & 0.0 & 0 & 0.0 & 21 & 56.8 \\
\hline \multirow{2}{*}{$\begin{array}{l}\text { Comlete remission } \\
\text { day } 33^{\text {b }}\end{array}$} & Yes & 266 & 95.0 & 47 & $0.819(0.025)$ & 82 & 100.0 & 161 & 100.0 & 23 & 62.2 \\
\hline & No & 14 & 5.0 & 11 & $0.214(0.110)$ & 0 & 0.0 & 0 & 0.0 & 14 & 37.8 \\
\hline
\end{tabular}

\section{Results}

Patient characteristics. The demographic and clinical characteristics of the 280 children with ALL treated in the Slovak Republic between 2002 and 2012 with patients' basic characteristics (sex, age, WBC, immunophenotype, specific cytogenetic aberrations, CNS status) and treatment response on day 8,15 and 33 of the total 280 patients and according to risk groups are summarized in Table I. Patient characteristics in the two time periods are provided in Table SI.

Event-free and overall survival. For the whole group of 280 patients, the 5-year EFS (+/- standard error (SE)) and OS rates were $79 \%$ (SE 2.6\%) and 86\% (SE 2.1\%), respectively. The corresponding estimates were 85\% (SE 4.1\%) and 95\% (SE 2.5\%) for the SR group ( $\mathrm{n}=82,29 \%$ of patients), $84 \%$ (SE 3.1\%) and $90 \%$ (SE $2.4 \%$ ) for the IR group ( $\mathrm{n}=161,58 \%$ of patients), and $42 \%$ (SE $8.9 \%$ ) and $48 \%$ (SE 9.6\%) for the HR group ( $n=37$, $13 \%$ of patients). (Table II, Figure 1, 2, 3).

Study vs non study patients. The overall outcome for patients enrolled in the ALL IC-BFM 2002 trial during 20022007 was not significantly different from that of patients treated in the $2^{\text {nd }}$ period, $(\mathrm{p}=0.491)$. The 5 -year EFS/OS rates were $77 \%$ (SE 3.5\%)/81\% (SE 3.8\%) for study patients and $85 \%$ (SE 3\%)/88\% (SE 3\%). There were significant differences in the outcome of patients age 6 to less than 10 years $(\mathrm{p}=0.044)$, and for patients with M3 bone marrow on day 15 $(\mathrm{p}=0.047)$, with better outcome for patients treated in the $2^{\text {nd }}$ period (Figure S1). 
Clinical characteristics and outcome (Table I). The EFS rates were similar for males and females $(\mathrm{p}=0.957)$, Figure S2. Age was highly predictive of outcome $(\mathrm{p}=0.001)$. As expected patients age 1 to less than 6 years had the best outcome with 5-year EFS and OS of 86\% (SE 3.1\%) and 93\% (SE 2.2\%), while patients 10 years and older had the worst outcome with 5-year EFS and OS of 65\% (SE 5.4\%) and 75\% (SE 4.9\%). Patients age 6 to $<10$ years had intermediate outcomes with 5-year EFS and OS of 82\% (SE 5.8\%) and 86\% (SE 5.3\%), Figure S3. Initial WBC was also highly predictive of outcome with 5-year EFS and OS rates $81 \%$ (SE 3.2\%) and $91 \%$ (SE 2.3\%) for those with an initial WBC $<20 \times 10^{9} / \mathrm{L}$, as compared to 66\% (SE 8.0\%) and 64\% (SE 8.4\%) for those with an initial WBC $\geq 100 \times 10^{9} / \mathrm{L}$ Figure S4. There was no difference in outcome based on precursor B-cell versus Tcell immunophenotype ( $p$ value for EFS 0.447 Figure S6). Patients with CNS 1 and 2 had a favorable outcome compared to those classified as CNS 3 ( $\mathrm{p}=0.039$ for OS and $\mathrm{p}=0.009$ for EFS; Figure S5).

Cytogenetic subgroups. ETV6/RUNX 1 was detected in 16\% of patients, and hyperdiploidy in 9\%. The 5-year EFS for these subgroups was similar to that of the overall group at $81 \%$ (SE $6.1 \%$ ) and EFS $83 \%$ (SE 8\%), respectively. Only a small percentage of patients were identified to have $B C R / A B L 1(1.8 \%)$ or $M L L / A F 4$ fusion (1.4\%), Table I.

Treatment response. Prednisone good response was achieved in $92 \%$ of patients (5-year EFS $81 \%$, SE 2.6\%) and PPR in $8 \%$ (5-year EFS 59.8\%, SE 10.5\%; p<0.003), Figure S7. Day 15 BM response was also highly predictive of outcome $(\mathrm{p}<0.0001)$. Patients with an M3 marrow had a 5-year

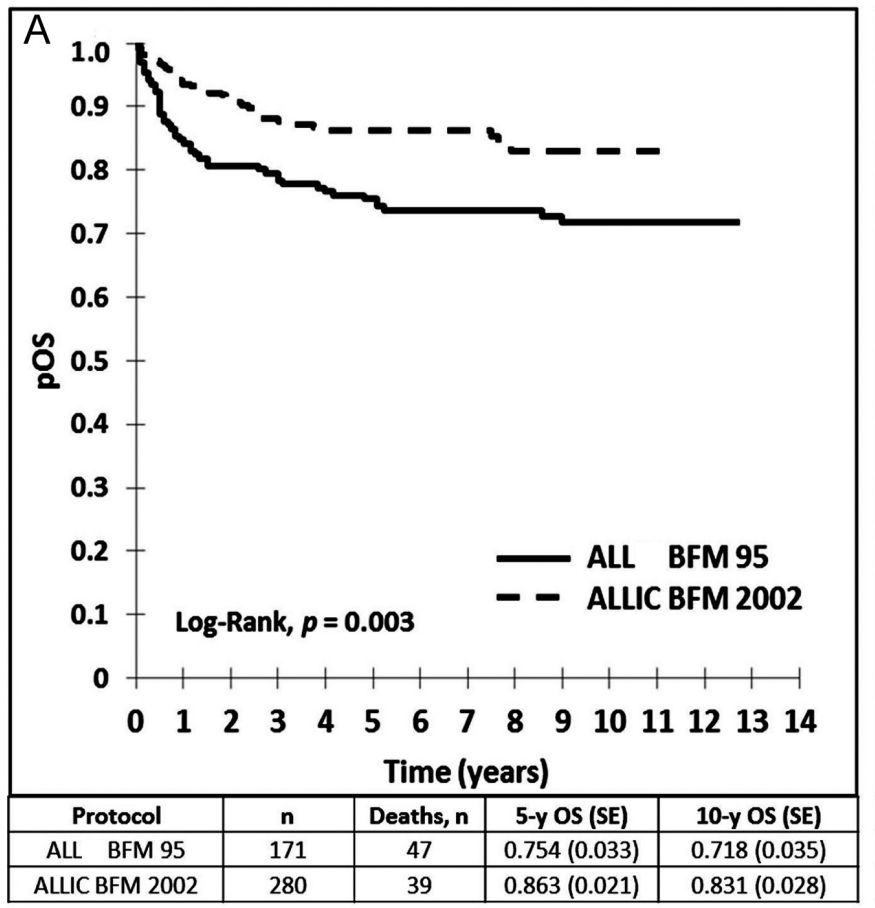

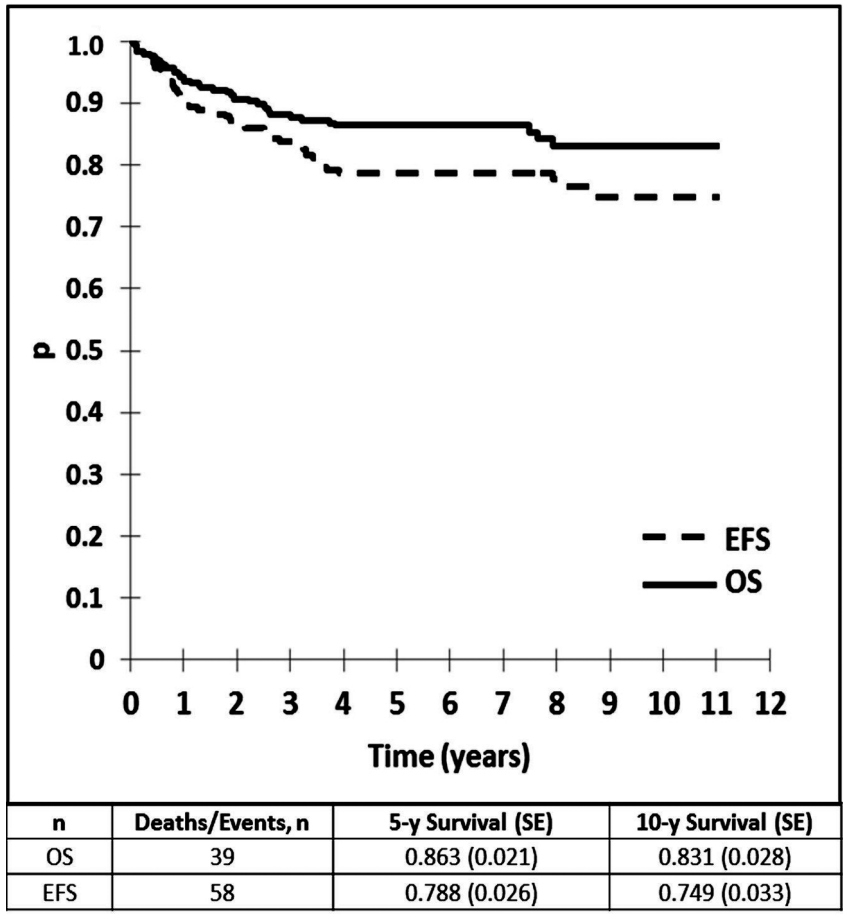

Figure 1. Survival and event free survival of all patients treated in Slovakia during period 2002-2012

EFS of only $29 \%$ (SE $11 \%$ ) compared to patients with an M1 (87\%, SE 2.6\%) or M2 marrow (71\% SE 5.9\%), Figure S8. Seven patients with BM M3 on day 15 were shifted

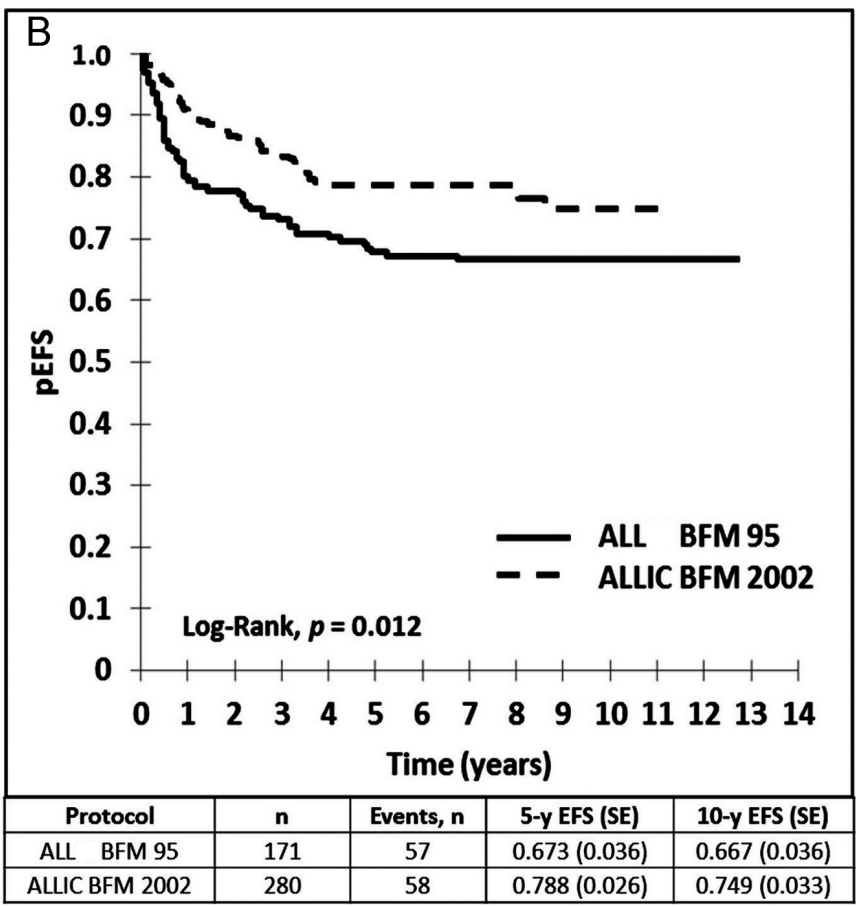

Figure 2. (A) Comparison of survival in BFM 95 and in ALLIC BFM 2002. (B) Comparison of event free survival in BFM 95 and in ALLIC BFM 2002 

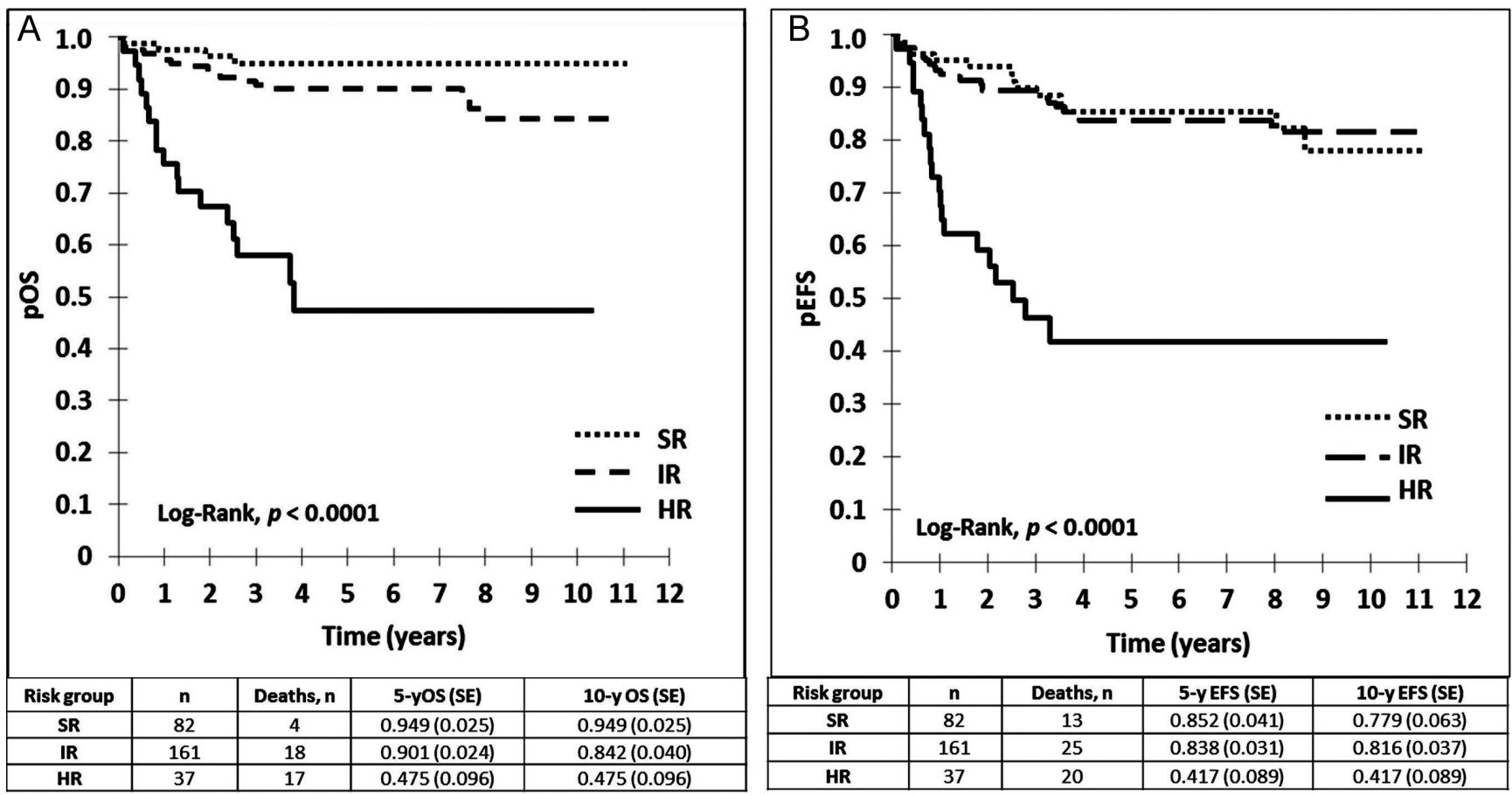

Figure 3. (A) Survival by risk groups in ALLIC BFM 2002. (B) Event free survival by risk groups in ALLIC BFM 2002.

from IR to HR. Patients who did not achieve remission on day $33(\mathrm{n}=14)$, had a very poor outcome $(\mathrm{p}<0.0001)$ with 5 -year EFS and OS only 21\% (SE 11\%) and 34\% (SE 13\%), Figure S9.
Events (Table II)

Remission failure and induction deaths. A total of 266/280 (95\%) patients achieved CR and 14 failed to achieve CR on day 33. Two patients died during induction ( $0.7 \%)$. Of the 12

Table 2. Treatment results

\begin{tabular}{|c|c|c|c|c|c|c|c|c|}
\hline & \multicolumn{2}{|c|}{ All } & \multicolumn{2}{|c|}{ SR } & \multicolumn{2}{|c|}{ IR } & \multicolumn{2}{|c|}{ HR } \\
\hline & $\mathbf{n}$ & $\%$ & $\mathbf{n}$ & $\%$ & $\mathbf{n}$ & $\%$ & $\mathbf{n}$ & $\%$ \\
\hline Overall & 280 & 100.0 & 82 & 100.0 & 161 & 100.0 & 37 & 100.0 \\
\hline Events (relapses + deaths) & 57 & 20.4 & 13 & 15.9 & 25 & 15.5 & 20 & 54.1 \\
\hline Deaths & 39 & 13.9 & 4 & 4.9 & 18 & 11.2 & 17 & 45.9 \\
\hline Death before CR & 2 & 0.7 & - & - & - & - & 2 & 5.4 \\
\hline Resistant disease & 1 & 0.4 & - & - & - & - & 1 & 2.7 \\
\hline Death in first CR & 15 & 5.4 & 1 & 1.2 & 8 & 5.0 & 5 & 13.5 \\
\hline During/after chemotherapy & 13 & 4.6 & 1 & 1.2 & 7 & 4.3 & 5 & 13.5 \\
\hline After stem cell transplantation & 2 & 0.7 & - & - & 1 & 0.6 & 1 & 2.7 \\
\hline Relapses & 42 & 15.0 & 11 & 13.4 & 18 & 11.2 & 13.0 & 35.1 \\
\hline Isolated BM & 29 & 10.4 & 7 & 8.5 & 13 & 8.1 & 9 & 24.3 \\
\hline Isolated CNS & 1 & 0.4 & 0 & 0.0 & 1 & 0.6 & 0 & 0.0 \\
\hline Isolated testes & 2 & 0.7 & 1 & 1.2 & 1 & 0.6 & 0 & 0.0 \\
\hline Combined CNS/BM involved & 5 & 1.8 & 1 & 1.2 & 2 & 1.2 & 2 & 5.4 \\
\hline Combined BM/other (without CNS) & 2 & 0.7 & 1 & 1.2 & 0 & 0.0 & 1 & 2.7 \\
\hline Secondary neoplasms & 2 & 0.7 & 1 & 1.2 & 1 & 0.6 & 0 & 0.0 \\
\hline Other relapses & 1 & 0.4 & 0 & 0.0 & 0 & 0.0 & 1 & 2.7 \\
\hline Stem cells transplantation & 23 & 8.2 & 4 & 4.9 & 7 & 4.3 & 12 & 32.4 \\
\hline SCT in $1 . \mathrm{CR}$ & 10 & 3.6 & 0 & 0.0 & 0 & 0.0 & 10 & 27.0 \\
\hline SCT in $2 . \mathrm{CR}$ & 11 & 3.9 & 3 & 3.7 & 6 & 3.7 & 2 & 5.4 \\
\hline SCT in 3. CR & 2 & 0.7 & 1 & 1.2 & 1 & 0.6 & 0 & 0.0 \\
\hline
\end{tabular}



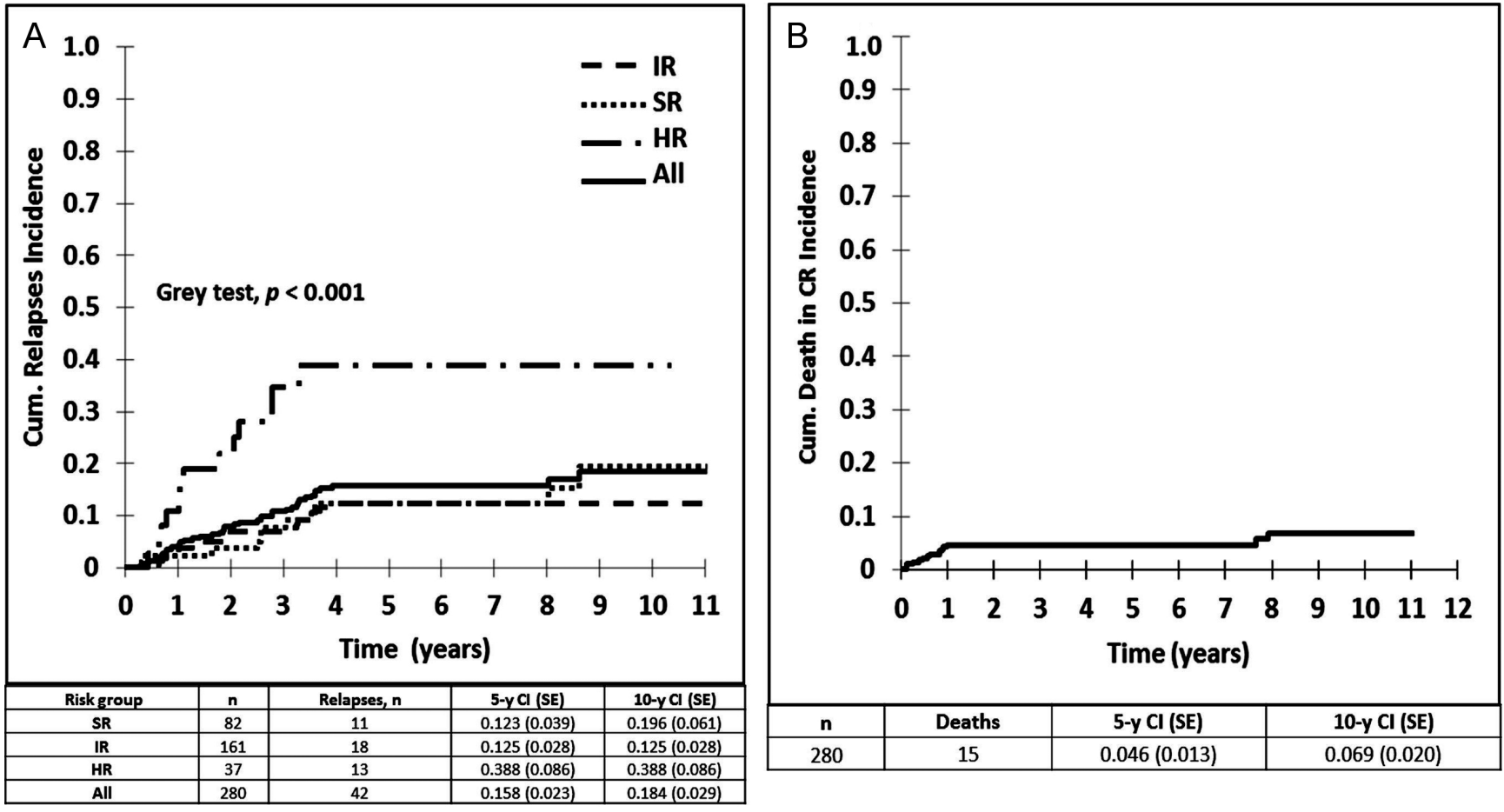

Figure 4. (A) Cumulative incidence of relapse, and by risk groups in ALLIC BFM 2002. (B) Cumulative incidence of death in complete remission in ALLIC BFM 2002.

patients who did not enter remission at day 33, 11 achieved remission at later time points, and 1 patient had resistant disease.

Death in CR. As a result of treatment - related events a total of 15 patients died in CR, with cumulative incidence rate (CIR) of $4.6 \%$ (SE 1.3) at 5 years (Figure 4). Of these deaths, 13 occurred in patients receiving chemotherapy and 2 occurred among the ten patients that underwent SCT in first remission.

Relapse. The most common cause of treatment failure was relapse with a 5-year CIR of $15.8 \%$ (SE 2.3\%), including $10.4 \%$ for isolated $\mathrm{BM}$ relapse, $0.4 \%$ for isolated CNS relapse, $1.8 \%$ for combined BM/CNS relapse, $0.7 \%$ for isolated testicular relapse, $0.7 \%$ for combined $\mathrm{BM} /$ other (without CNS), $0.4 \%$ of other relapses. The 10-year CIR of relapse was slightly higher at $18.0 \%$ (SE 2.9\%). The 5-year CIR for relapse differed among the risk groups: $12.3 \%$ (SE 3.9\%) for SR, $12.5 \%$ (SE 2.8\%) for IR, and $38.8 \%$ (SE 8.6\%) for $\mathrm{HR}(\mathrm{p}<0.001$; Figure 4$)$.

Second malignant neoplasms (SMN). Two SMN occurred, one patient developed an aggressive histiocytic sarcoma during maintenance therapy and died within 6 months and another patient developed myelodysplasia with monosomy $7,3.5$ years after ALL was diagnosed and underwent allogenic HSCT and is alive in $2^{\text {nd }} \mathrm{CR}$.

Hematopoietic stem cell transplantation (HSCT). Ten patients $(0.4 \%)$ underwent HSCT from a matched sibling or matched unrelated donor in first remission. Four have died (one due to post-transplant lymphoproliferative disorder, one due to graft-versus-host disease and 2 from relapse) and six remain in first remission. Nine patients were transplanted in $2^{\text {nd }} \mathrm{CR}, 5$ of whom are alive in remission, and 4 who died (1 due to aspergillosis, 1 due to graft-versus-host disease and 2 after another relapse). Two patients were transplanted in CR3, both of whom subsequently died.

\section{Discussion}

Each year in the Slovak Republic, which has about 1.1 million children, approximately 40 pediatric leukemia cases are diagnosed, including 30 cases of acute lymphoblastic leukemia, 6-8 cases of acute myeloid leukemia, and 1-2 cases of chronic myeloid leukemia [16, 23, 24]. Children with leukemia are treated in 3 centers, which are well distributed across Slovakia. In Bratislava there are about 50\% of patients and in Banska Bystrica and Kosice equally about $25 \%$ of patients.

Treatment and results in historical perspective. From 1971 until 1991, a variety of different treatment regimens derived from those used in the United States were used to treat children with ALL $[13,14,15]$. The 10-year EFS and OS rates in this period were $46 \%$ and $50 \%$, respectively [16]. Starting in 1997, BFM-based ALL treatment regimens have been used. Initially from 1997-2001, the ALL BFM 95 regimen was adopted and children were treated with this regimen in all 
of the three centers in the Slovak Republic, but not as part of a formal clinical trial. The 10 -year EFS and OS rates from this period were $67 \%$ and $72 \%$, with $2.9 \%$ induction deaths and $10.8 \%$ deaths in $1^{\text {st }} \mathrm{CR}$, and a $20 \%$ relapse rate [16]. In order to participate in the formal ALL IC-BFM 2002 trial, several important steps were taken including standardized methods for diagnosis and treatment response, development of a common database to facilitate country-wide randomization and data capture, and institution of standardized supportive care guidelines across the three centers.

Current results. In this report, we present the results of 280 patients, treated in the Slovak Republic from 2002 - 2012. The main result of our analyses is that the 5-year EFS and OS rates were $79 \%$ and $86 \%$, which are significantly better than those obtained using the same BFM-95 based regimen in $1997-2001$ ( $p=0.012$ for EFS and $p=0.003$ for OS; Figure 2). Regarding comparison with larger groups; our results compare favorably to those of the total ALL IC BFM 2002 trial (5-year EFS 74\%, OS 82\%) [12] and are very similar to those achieved in Western Europe in the ALL BFM 95 trial that utilized the same treatment regimen. Moricke et al report results for 2283 pts with 6-years EFS of $79.6 \%$ and OS of $86.3 \%[25,26]$ and almost as good as those obtained in the most recent reports of AEIOP/BFM ALL 2000 trial (7-year EFS and OS of $80.4 \%$ and $91.8 \%$, respectively [27]).

One important potential cause for lower survival rates in countries with lower incomes and/or less familiarity with intensive therapy are higher rates of treatment-related mortality. The rate of induction death $(0.7 \%)$ in this study is essentially the same as that in the ALL BFM 95 study (25). However, we encountered higher rates of death in $1^{\text {st }}$ CR. Prior to 1997, the rate of death in $1^{\text {st }} \mathrm{CR}$ decreased gradually in Slovak protocols from $10.4 \%$ to $1.8 \%$, but then significantly increased (10.8\%) with introduction of the ALL BFM 95 protocol in Slovakia in 1997 due to insufficient experience with intensive BFM-type therapy (16). Since 2002, the cumulative incidence of death in $1^{\text {st }} \mathrm{CR}$ decreased to $4.6 \%$, which is still about two times higher than the results of ALL BFM 95 (2.1\%) and three times higher than current achievements of leading international collaborative ALL treatment groups (1.4\%) (27). Thus, decreasing the rate of death in remission remains a important challenge in Slovakia.

Risk groups stratification. Patient in the SR group $(\mathrm{n}=82)$ achieved excellent results with 5-year EFS and OS of $85 \%$ and 95\%, respectively. Fifteen events occurred in the SR group (4 deaths and 11 relapses). In the IR group, EFS and OS were $84 \%$ and $90 \%$ ( $n=161$ patients, 24 events, 18 relapses). Our results in the SR and IR groups are better than overall outcomes for these groups in the whole ALL IC BFM 2002 trial. While the number of HR patients was small ( $\mathrm{n}=37$, with 20 events and 13 relapses), our results in this group are quite unsatisfactory and need improvement due to high toxicity.

Relapse rate. The relapse rate for children with ALL in Slovakia decreased from $42 \%$ to $35 \%$ before the introduction of
BFM based therapy, with a $9 \%$ rate of CNS relapse. These rates have decreased significantly since the introduction of BFMbased therapy in 1997, with cumulative incidence of relapse of $20.5 \%$ (CNS $1.8 \%$ ) in $1997-2001$, and $15.4 \%$ with only $0.4 \%$ CNS in 2002-12. The biggest challenge is for HR patients who had a very high CIR rate of $39.5 \%$. Although patient numbers are small in this group in Slovakia $(n=37)$, this appears to be worse than the overall results of international ALL IC BFM 2002 (25.2\%), but about the same as achieved in ALL BFM 95 (38\%) [25].

Study vs non study patients. The patients enrolled in ALL IC BFM 2002 in $2002-2007(n=140)$ achieved 5-year EFS and OS of $77 \%$ and $85 \%$. The cohort $(n=140)$ enrolled in 2008 2012 after the study was closed had a trend toward improved outcome, with 5 -year EFS and OS of $81 \%$ and $88 \%$. While it is not statistically different in overall results (significant statistical difference was achieved in age group 6 to less than 10 years old and in M3 marrow on day 15), there is a trend toward better EFS/OS in the latter period. The results suggest that outcome may be improving over time with increased familiarity with the treatment regimen.

Response to treatment. Response in BM on day 15 had significant impact on outcome, patients with good response on day $15(67 \%)$ achieved 5 years EFS 87\% and those with bone marrow $\mathrm{M} 3$ response has significantly worse outcome. On day $33,95 \%$ of patients achieved complete remission. These results are consistent with those published by Stary.

Cytogenetic. We observed lower rates of specific sentinel chromosome translocations and numerical abnormalities than those reported by larger groups. This is likely due to technical factors, and efforts are ongoing to improve cytogenetic methodology in Slovakia.

\section{Conclusion}

Slovak Republic participation in the ALL IC BFM 2002 trial resulted in statistically significant improvement in 5-year EFS and OS, due to decreases in CIR of relapse, and in induction and treatment related deaths over past decade. Our results are almost as good as those achieved by the larger BFM group in Western Europe in the late 1990s using the same treatment approach. This improvement was achieved not by changing treatment strategies, but by several other factors: development of central diagnostic infrastructure, improvements in supportive care, familiarities with BFM-based treatment and participation in the intercontinental clinical trial. However, our results for patients in the HR group remain quite unsatisfactory and need improvement. The next challenge in treatment of childhood ALL in the Slovak Republic is to adopt contemporary approaches to MRD-based risk stratification to facilitate more precise patient allocation to risk groups [27, $28,29,30,31]$.

Supplementary information is available in the online version of the paper. 
Acknowledgements: The authors are grateful to the ALL-IC BFM group, particularly Prof. Martin Schrappe, I- BFM chair, for their support of this study. They also wish to acknowledge Lucia Copakova, MD for their assistance with cytogenetic and PCR testing; Olga Babusikova, MD, PhD for her assistance with flow cytometry; and Prof. Jan Cap, MD, PhD and Olga Mazariova for their assistance with cytomorphology. Finally, they wish to thank Stephen P. Hunger in the Ergen Family Chair in Pediatric Cancer, as well as all the physicians, nurses, patients and families involved in the study. This project was supported in part by a grant from the Slovak-American Foundation to Alexandra Kolenova and as well by grant from Ministry of Health in Slovakia (MZ SR 2012/7-UKBA-7).

\section{References}

[1] INABA H, GREAVES M, MULLIGHAN CG. Acute lymphoblastic leukaemia. Lancet 2013; 381: 1943-55. http://dx.doi. org/10.1016/S0140-6736(12)62187-4

[2] PUI C. Toward a total cure for acute lymphoblastic leukemia. J Clin Oncol 2009; 27(: 5121-3.

[3] STANULLA M, SCHRAPPE M. Treatment of childhood acute lymphoblastic leukemia. Semin Hematol 2009; 46: 52-63. http://dx.doi.org/10.1053/j.seminhematol.2008.09.007

[4] SCHRAPPE M, NACHMAN J, HUNGER S, SCHMIEGELOW $\mathrm{K}$, CONTER V et al. Educational symposium on long-term results of large prospective clinical trials for childhood acute lymphoblastic leukemia (1985-2000)؛ Leukemia 2010; 24: 253-4. http://dx.doi.org/10.1038/leu.2009.276

[5] HUNGER SP, LU X, DEVIDAS M, CAMITTA BM, GAYNON PS et al. Improved survival for children and adolescents with acute lymphoblastic leukemia between 1990 and 2005: A report from the children's oncology group. J Clin Oncol 2012; 30: 1663-1669. http://dx.doi.org/10.1200/ JCO.2011.37.8018

[6] MITCHELL C, RICHARDS S., HARRISON CJ, EDEN T „Long-term follow-up of the United Kingdom medical research council protocols for childhood acute lymphoblastic leukaemia, 1980-2001."Leukemia 2010; 24(2): 406-18. http:// dx.doi.org/10.1038/leu.2009.256

[7] MORICKE A, ZIMMERMAN M, REITER A, HENZE G, SCHRAUDER A. et al. Long-term results of five consecutive trials in childhood acute lymphoblastic leukemia performed by the ALL-BFM study group from 1981 to 2000. Leukemia 2010; 24: 265-84. http://dx.doi.org/10.1038/leu.2009.257

[8] SALZER WL, DEVIDAS M, CARROLL WL, WINICK N, PULLEN J et al. Long-term results of the pediatric oncology group studies for childhood acute lymphoblastic leukemia 1984-2001: a report from the children's oncology group. Leukemia 2010; 24: 355-70. http://dx.doi.org/10.1038/ leu.2009.261

[9] CONTER V, BARTRAM CR, VALSECCHI MG, SCHRAUDER A, PANZER-GRUMAYER R et al. Molecular response to treatment redefines all prognostic factors in children and adolescents with B-cellprecursor acute lymphoblastic leukemia: Results in 3184 patients of the AIEOPBFM ALL 2000 study. Blood 2010; 115: 3206-3214. http://dx.doi.org/10.1182/ blood-2009-10-248146
[10] SCHRAPPEM, REITER A, ZIMMERMANN M, HARBOTT J, LUDWIG WD et al. Long-term results of four consecutive trials in childhood ALL performed by the ALL-BFM study group from 1981 to 1995. Berlin-Frankfurt-Münster. Leukemia 2000; 14: 2205-22. http://dx.doi.org/10.1038/sj.leu.2401973

[11] HUNGER SP. Expanding clinical trial networks in pediatric acute lymphoblastic leukemia. J Clin Oncol. 2014; 32(3): 169-70. http://dx.doi.org/10.1200/JCO.2013.53.2754

[12] STARY J, ZIMMERMANN M, CAMPBELL M, CASTILLO L, DIBAR E et al. Intensive Chemotherapy for Childhood Acute Lymphoblastic Leukemia: Results of the Randomized Intercontinental Trial ALL IC-BFM 2002. J Clin Oncol. 2014 20; 32: 174-84. http://dx.doi.org/10.1200/JCO.2013.48.6522

[13] HOLLANDJF, GLIWENDELL O. Chemotherapy of acutelymphocytic leukemia of childhood Cancer 1972; 30: $1480 \mathrm{http} / / /$ dx.doi.org/10.1002/1097-0142(197212)30:6<1480::AIDCNCR2820300611>3.0.CO;2-3

[14] CAP J, CESNAK D, KAISEROVA E, FOLTINOVA A, MISIKOVA $\mathrm{Z}$ et al. Treatment of acute lymphoblastic leukemia in children in Slovakia (in Slovak). Čs Pediatr 1984; 39: 78-81.

[15] CAP J, FOLTINOVA A, MISIKOVA Z, KAISEROVA E Two decades of treatment of children with acute lymphoblastic leukemia in Slovakia (in Slovak). Čs Pediatr 1996; 51: 63-69.

[16] KAISEROVA E, BUBANSKA E, ORAVKINOVA I, SUBOVA Z, KOLENOVA A et al. Results of acute lymphoblastic treatment in children in the Slovak Republic. Memo 2011; 4: 190-5. http://dx.doi.org/10.1007/s12254-011-0283-2

[17] BENE MC, CASTOLDI G, KNAPP W, LUDWIG W D, MATUTES, E. et al. Proposals for the immunological classification of acute leukemias. European Group for the Immunological Characterization of Leukemias (EGIL). Leukemia 1995; 9: 1783-6.

[18] SCHLIEBEN S, BORKHARDT A, REINISH I, RITTER$\mathrm{BACH}$ J, JANSSEN et al. Incidence and clinical outcome of children with BCR/ABL-positive acute lymphoblastic leukemia (ALL). A prospective RT-PCR study based on 673 patients enrolled in the German pediatric multicenter therapy trials ALL-BFM-90 and CoALL-05-92. Leukemia 1996; 10: 957-63.

[19] FRONKOVA E, MEJSTRIKOVA E, AVIGAD S, CHIK KW, CASTILLO L et al. Minimal residual disease (MRD) analysis in the non-MRD-based ALL IC-BFM 2002 protocol for childhood ALL: is it possible to avoid MRD testing? Leukemia 2008; 22: 989-97. http://dx.doi.org/10.1038/leu.2008.22

[20] KAPLAN EL, MEIER P. Nonparametric estimation from incomplete observations. J. Am. Stat. Assoc 1958; 53: 457-81. http://dx.doi.org/10.1080/01621459.1958.10501452

[21] MANTEL N. Evaluation of survival data and two new rank order statistics arising in itsconsideration. Cancer Chemother Rep 1966; 50: 163-70.

[22] GRAY RJ. A class of K-sample tests for comparing the cumulative incidence of a competing risk. Ann Stat 1988; 16: 1141-1154. http://dx.doi.org/10.1214/aos/1176350951

[23] KOLENOVA A, KAISEROVA E, SEJNOVA D, BUBANSKA E, ORAVKINOVA I et al. Development of treatment and clinical results in childhood acute myeloid leukemia in the Slovak 
Republic. Memo 2013; 6: 46-53. http://dx.doi.org/10.1007/ $\underline{\text { s12254-012-0052-X }}$

[24] KAISEROVA E, BUBANSKA E, ORAVKINOVA I, STANCOKOVA T, SUBOVA $\mathrm{Z}$ et al. Incidence and curability of malignancies in childhood in Slovak republic. Onkologia (Bratislava) 2006; 3: 180-6.

[25] MORICKE A, REITER A, ZIMMERMANN M, GADNER H, SRANULLA M et al. German-Austrian-Swiss ALL-BFM Study Group. Risk-adjusted therapy of acute lymphoblastic leukemia can decrease treatment burden and improve survival: treatment results of 2169 unselected pediatric and adolescent patients enrolled in the trial ALL-BFM 95. Blood 2008; 111: 4477-89. http://dx.doi.org/10.1182/blood-2007-09-112920

[26] ARICO M, VALSECCHI MG, RIZZARI C, BARISONE E, BIONI A et al. Long-term results of the AIEOP-ALL-95 Trial for Childhood Acute Lymphoblastic Leukemia: insight on the prognostic value of DNA index in the framework of BerlinFrankfurt-Muenster based chemotherapy. J Clin Oncol 2008; 26: 283-9. http://dx.doi.org/10.1200/JCO.2007.12.3927

[27] Conter V, BARTRAM CR, VALSECCHI MG, SHRADUER A, PANZER-GRUNMAYER R et al. Molecular response to treatment redefines all prognostic factors in children and adolescents with B-cell precursor acute lymphoblastic leukemia: results in 3184 patients of the AIEOP-BFM ALL 2000 study. Blood 2010; 115: 3206-14. http://dx.doi.org/10.1182/ blood-2009-10-248146
[28] FLOHR T, SCHRAUDER A, CAZZANIGA G, PANZERGRUNMAYER R, VAN DER VELDEN et al.: Minimal residual disease-directed risk stratification using real-time quantitative PCR analysis of immunoglobulin and T-cell receptor gene rearrangements in the international multicenter trial AIEOP-BFM ALL 2000 for childhood acute lymphoblastic leukemia. Leukemia 2008, 22: 771-82. http://dx.doi. org/10.1038/leu.2008.5

[29] ECKERT C, HENZE G, SEEGER K, HAGEDORN N, MANN $\mathrm{G}$ et al. Use of allogeneic hematopoietic stem-cell transplantation based on minimal residual disease response improves outcomes for children with relapsed acute lymphoblastic leukemia in the intermediate-risk group. J Clin Oncol 2013; 31: 2736-42. http://dx.doi.org/10.1200/JCO.2012.48.5680

[30] BALDZUZZI A, DI MAIO L, SLVESTRI D, SONGIA S, BONANOMI S et al. Minimal residual disease before and after transplantation for childhood acute lymphoblastic leukaemia: is there any room for intervention? Br J Haematol. 2014; 164: 396-408. http://dx.doi.org/10.1111/bjh.12639

[31] KOLENOVA A, HIKKEL I, ILENCIKOVA D, HIKKELOVA $\mathrm{M}$, SEJNOVA D et al. Minimal residual disease detection using real-time quantitative PCR analysis of immunoglobulin and $\mathrm{T}$-cell receptor gene rearrangements in the non-MRD-based ALL IC-BFM 2002 protocol for childhood ALL: Slovak experience. Neoplasma 2010; 57: 552-61. http://dx.doi.org/10.4149/ neo $2010 \quad 06 \quad 552$ 


\title{
Supplementary Information
}

\section{Improved outcome for children and adolescent with acute lymphoblastic leukemia in the first decade of the 21 st century: a report from the Slovak Republic}

\begin{abstract}
A. KOLENOVA ${ }^{1, *}$, E. KAISEROVA ${ }^{1}$, M. MAKOHUSOVA ${ }^{1,4}$, Z. SUBOVA ${ }^{1}$, E. BUBANSKA ${ }^{2}$, I. ORAVKINOVA ${ }^{3}$, P. SVEC S $^{1}$ O. FABRI ${ }^{1}$, S. P. HUNGER ${ }^{5}$,
\end{abstract} S. SUFLIARSKA ${ }^{1}$, S. HORAKOVA ${ }^{1}$, V. MRAZOVA ${ }^{4}$, J. STARY ${ }^{6}$

${ }^{1}$ Department of Pediatric Hematology and Oncology, Comenius University - Medical School and University Children's Hospital, Bratislava, Slovak republic; ${ }^{2}$ Department of Pediatric Oncology and Hematology, Children's University Hospital, Banská Bystrica, Slovak republic; ${ }^{3}$ Department of Pediatric Hematology and Oncology, University Children's Hospital Kosice, Slovak Republic; ${ }^{4}$ Department of Chemistry, University of SS. Cyril and Methodius, J. Herdu 2, Trnava,Slovak Republic; ${ }^{5}$ University of Pennsylvania Perelman School of Medicine and The Children's Hospital of Philadelphia, Philadelphia PA USA; ${ }^{6}$ Department of Pediatric Oncology and Hematology, Charles University and University Hospital Motol, Czech Republic

*Correspondence: sasa.kolenova@gmail.com

A

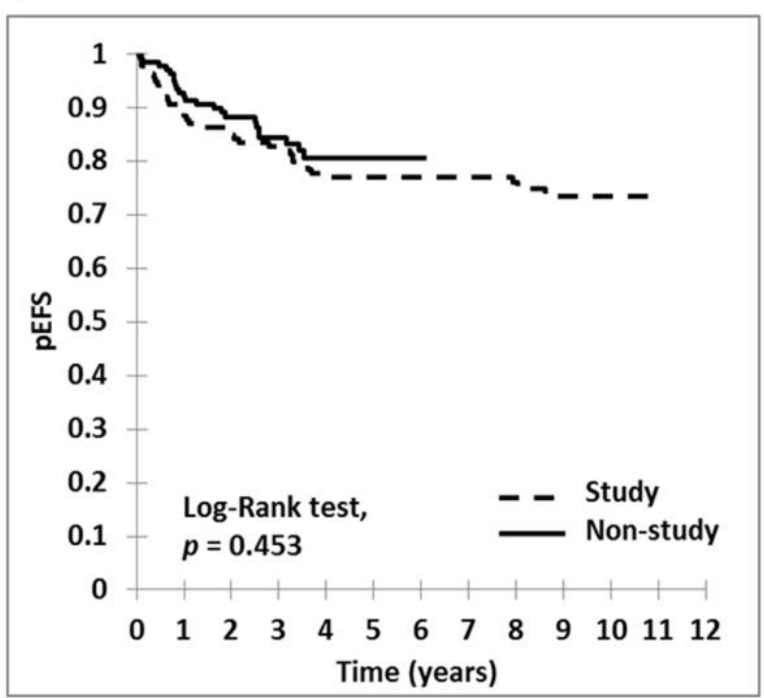

\begin{tabular}{cccc}
\hline Treatment group & $\mathbf{n}$ & Events, $\mathbf{n}$ & 5-yEFS \\
\hline Study & 140 & 35 & $0.771(0.035)$ \\
Non-study & 140 & 23 & $0.807(0.038)$ \\
\hline
\end{tabular}

B

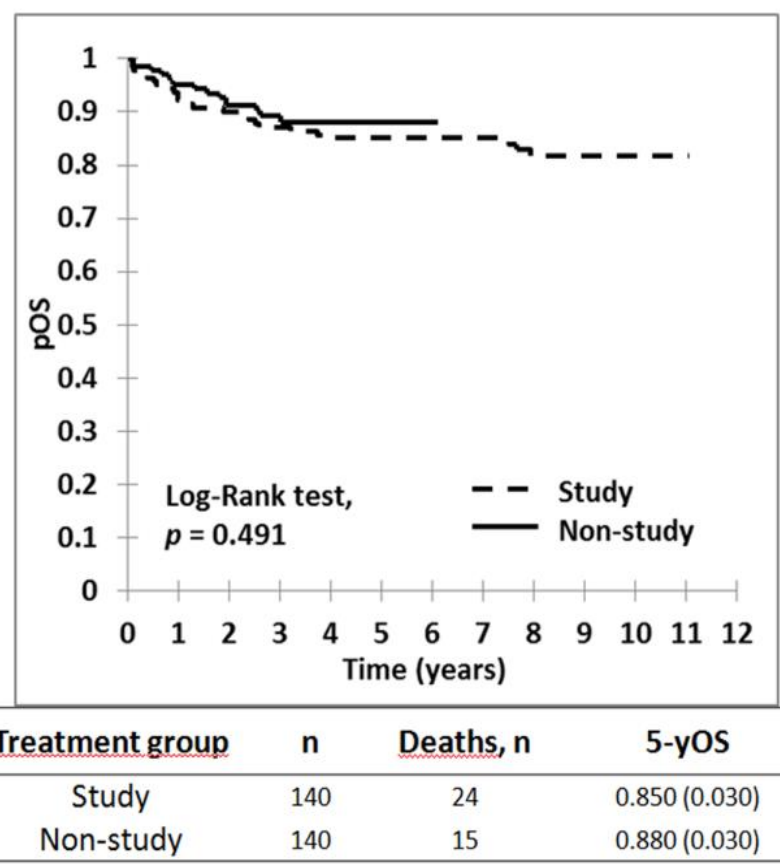

Figure S1. (A) Comparison of survival in period 2002-2007 (study) and in 2008-2012 (non study). (B) Comparison of event free survival in period 20022007 (study) and in 2008-2012 (non study) 
Table S1. Study and non-study patients' characteristics

\begin{tabular}{|c|c|c|c|c|c|c|c|c|c|c|}
\hline \multirow[b]{2}{*}{ Variable } & & \multicolumn{4}{|c|}{ Study group $($ total $n=140)$} & \multicolumn{5}{|c|}{ Non study group (total $n=140$ ) } \\
\hline & & $\mathbf{n}$ & $\%$ & $\begin{array}{c}\text { Events, } \\
\text { n }\end{array}$ & 5-y EFS (SE) & $\mathbf{n}$ & $\%$ & Events, $\mathbf{n}$ & 5-y EFS (SE) & $p$ \\
\hline & All & 140 & 100.0 & 35 & $0.771(0.035)$ & 140 & 100.0 & 23 & $0.815(0.041)$ & 0.453 \\
\hline \multirow[t]{2}{*}{ Sex } & Male & 88 & 62.9 & 22 & $0.773(0.045)$ & 97 & 69.3 & 17 & $0.789(0.047)$ & 0.655 \\
\hline & Female & 52 & 37.1 & 13 & $0.769(0.058)$ & 43 & 30.7 & 6 & $0.848(0.059)$ & 0.464 \\
\hline \multirow[t]{3}{*}{ Age } & 1 to less than $6 y$ & 71 & 50.7 & 11 & $0.873(0.03 .9)$ & 74 & 52.9 & 10 & $0.834(0.050)$ & 0.584 \\
\hline & 6 to less than $10 y$ & 25 & 17.9 & 7 & $0.720(0.09 .0)$ & 27 & 19.3 & 1 & $0.963(0.036)$ & $0.044^{\mathrm{a}}$ \\
\hline & $10 \mathrm{y}$ and older & 44 & 31.4 & 17 & $0.636(0.073)$ & 39 & 27.9 & 12 & $0.661(0.081)$ & 0.768 \\
\hline \multirow[t]{3}{*}{ Initial WBC $(/ \mu \mathrm{L})$} & Less than 20000 & 88 & 62.9 & 19 & $0.818(0.041)$ & 84 & 60.0 & 14 & $0.794(0.051)$ & 0.736 \\
\hline & 20000 to less than $100 \times 10^{9} / \mathrm{L}$ & 38 & 27.1 & 9 & $0.763(0.069)$ & 34 & 24.3 & 4 & $0.882(0.055)$ & 0.314 \\
\hline & 100000 and over & 14 & 10.0 & 7 & $0.500(0.134)$ & 22 & 15.7 & 5 & $0.773(0.089)$ & 0.093 \\
\hline \multirow[t]{3}{*}{ CNS status } & CNS1 & 108 & 77.1 & 24 & $0.806(0.038)$ & 95 & 67.9 & 14 & $0.812(0.048)$ & 0.826 \\
\hline & $\mathrm{CNS} 2$ & 24 & 17.1 & 7 & $0.708(0.093)$ & 33 & 23.6 & 4 & $0.874(0.059)$ & 0.099 \\
\hline & CNS3 & 8 & 5.7 & 4 & $0.500(0.177)$ & 12 & 8.6 & 5 & $0.533(0.161)$ & 0.832 \\
\hline \multirow[t]{2}{*}{ Precursor } & Precursor T & 20 & 14.3 & 5 & $0.750(0.097)$ & 22 & 15.7 & 5 & $0.767(0.092)$ & 0.739 \\
\hline & Precursor B & 120 & 85.7 & 30 & $0.775(0.038)$ & 118 & 84.3 & 18 & $0.815(0.041)$ & 0.444 \\
\hline \multirow[t]{3}{*}{ ETV6/ RUNX 1} & Negative & 118 & 84.3 & 28 & $0.788(0.038)$ & 105 & 75.0 & 18 & $0.800(0.044)$ & 0.830 \\
\hline & Positive & 16 & 11.4 & 3 & $0.813(0.098)$ & 30 & 21.4 & 5 & $0.807(0.079)$ & 0.985 \\
\hline & No data & 6 & 4.3 & 4 & $0.333(0.192)$ & 5 & 3.6 & 0 & $1.000(0.000)$ & - \\
\hline \multirow[t]{3}{*}{ Hyperdiploidy } & Negative & 126 & 90.0 & 32 & $0.770(0.037)$ & 124 & 88.6 & 21 & $0.807(0.039)$ & 0.529 \\
\hline & Positive & 13 & 9.3 & 2 & $0.846(0.100)$ & 13 & 9.3 & 2 & $0.750(0.153)$ & 0.894 \\
\hline & No data & - & - & - & - & 3 & 2.1 & 0 & $1.000(0.000)$ & - \\
\hline \multirow[t]{2}{*}{ T lineage NCI risk criteria } & Standard risk & 3 & 2.1 & 0 & $1.000(0.000)$ & 5 & 3.6 & 1 & $0.800(0.179)$ & - \\
\hline & High risk & 17 & 12.1 & 5 & $0.706(0.111)$ & 17 & 12.1 & 4 & $0.755(0.107)$ & 0.574 \\
\hline \multirow[t]{2}{*}{ Non-T lineage NCI risk criteria } & Standard risk & 69 & 49.3 & 12 & $0.855(0.042)$ & 80 & 57.1 & 8 & $0.874(0.043)$ & 0,727 \\
\hline & High risk & 51 & 36.4 & 18 & $0.667(0.066)$ & 38 & 27.1 & 10 & $0.697(0.083)$ & 0.804 \\
\hline \multirow[t]{2}{*}{ Prednisone response } & Good & 134 & 95.7 & 31 & $0.791(0.035)$ & 123 & 87.9 & 18 & $0.825(0.039)$ & 0.491 \\
\hline & Poor & 6 & 4.3 & 4 & $0.333(0.192)$ & 17 & 12.1 & 5 & $0.688(0.118)$ & 0.074 \\
\hline \multirow[t]{3}{*}{ BM day 15} & M1 & 98 & 70.0 & 13 & $0.888(0.032)$ & 95 & 67.9 & 12 & $0.837(0.045)$ & 0.412 \\
\hline & M2 & 31 & 22.1 & 12 & $0.645(0.086)$ & 35 & 25.0 & 7 & $0.786(0.073)$ & 0.322 \\
\hline & M3 & 11 & 7.9 & 10 & $0.091(0.087)$ & 10 & 7.1 & 4 & $0.583(0.161)$ & $0.047^{\mathrm{a}}$ \\
\hline \multirow[t]{2}{*}{ Completed remission on day 33} & Yes & 130 & 92.9 & 27 & $0.815(0.034)$ & 136 & 97.1 & 20 & $0.824(0.037)$ & 0.838 \\
\hline & No & 10 & 7.1 & 8 & $0.200(0.126)$ & 4 & 2.9 & 3 & $0.250(0.217)$ & 0.981 \\
\hline \multirow[t]{3}{*}{ BFM risk criteria } & SR & 45 & 32.1 & 7 & $0.889(0.047)$ & 37 & 26.4 & 7 & $0.786(0.081)$ & 0.288 \\
\hline & IR & 80 & 57.1 & 16 & $0.813(0.044)$ & 81 & 57.9 & 9 & $0.871(0.041)$ & 0.372 \\
\hline & HR & 15 & 10.7 & 12 & $0.200(0.103)$ & 22 & 15.7 & 8 & $0.614(0.109)$ & $0.022^{\mathrm{a}}$ \\
\hline
\end{tabular}


A

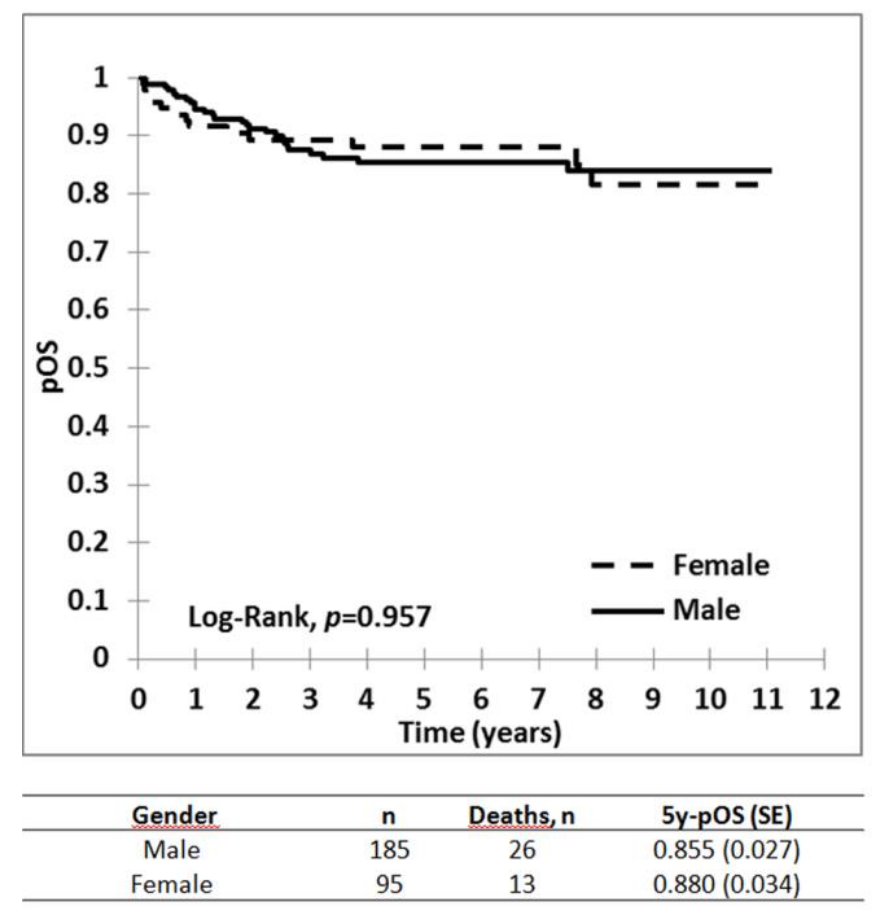

B

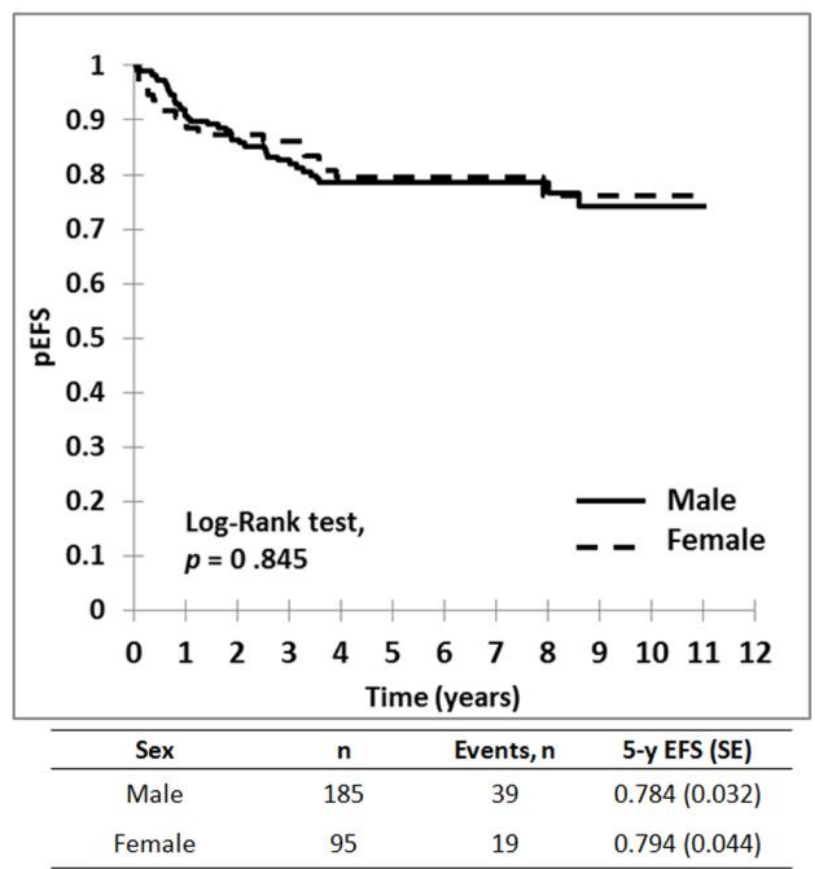

Figure S2. (A) Survival by sex. (B) Event free survival by sex.

A

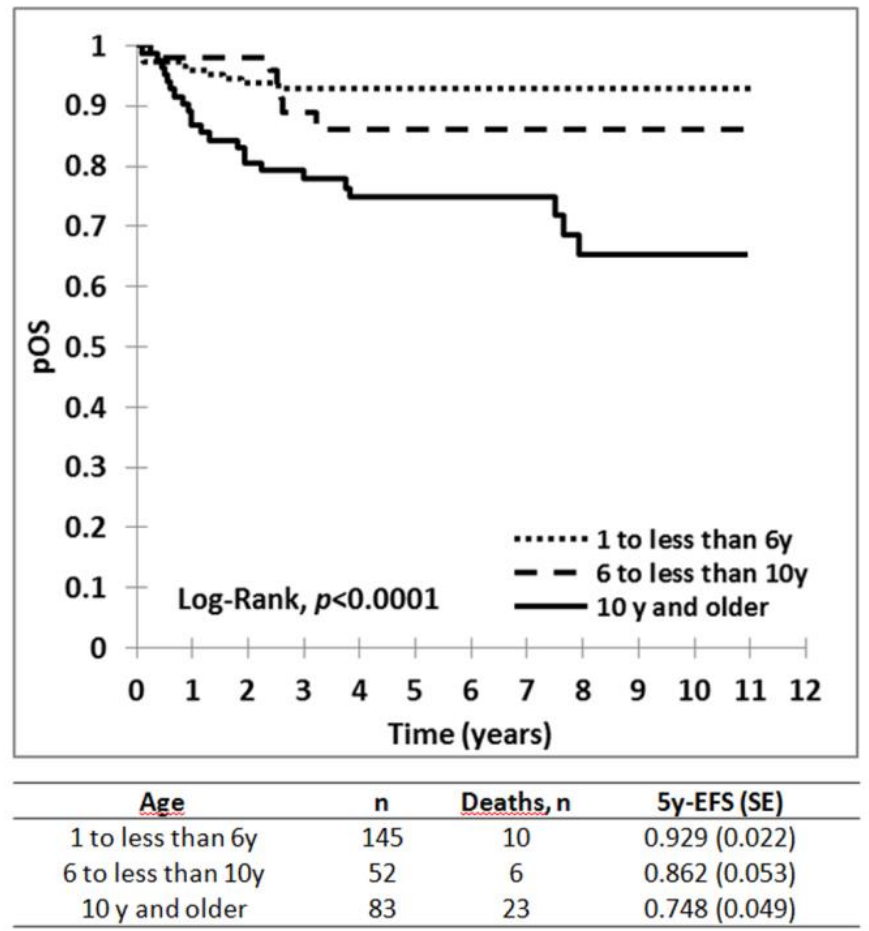

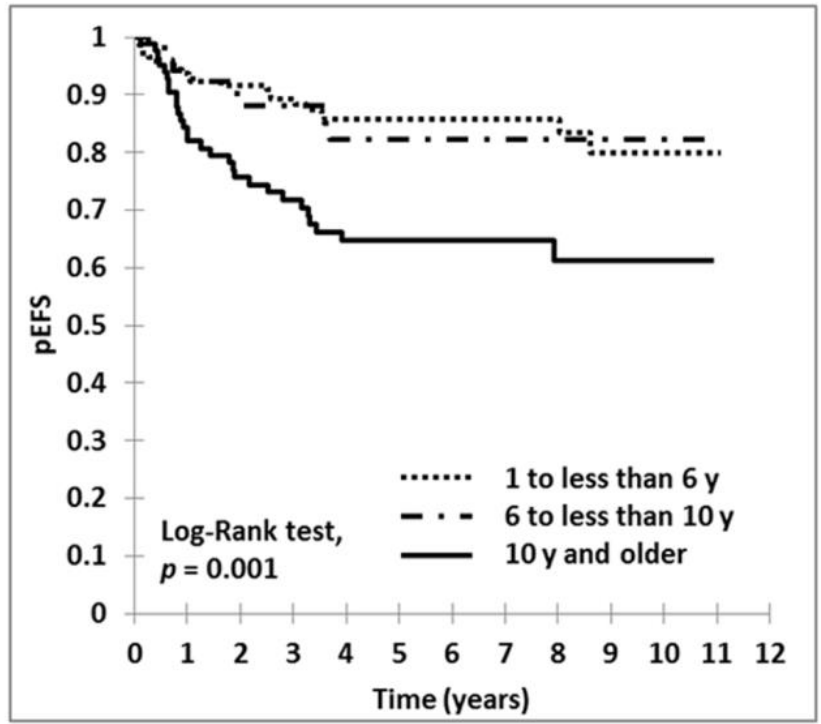

\begin{tabular}{cccc}
\hline Age & $\mathbf{n}$ & Events, $\mathbf{n}$ & 5-y EFS (SE) \\
\hline 1 to less than $6 y$ & 145 & 21 & $0.857(0.031)$ \\
6 to less than $10 \mathrm{y}$ & 52 & 8 & $0.822(0.058)$ \\
$10 \mathrm{y}$ and older & 83 & 29 & $0.647(0.054)$ \\
\hline
\end{tabular}

Figure S3. (A) Survival by age. (B) Event free survival by age 

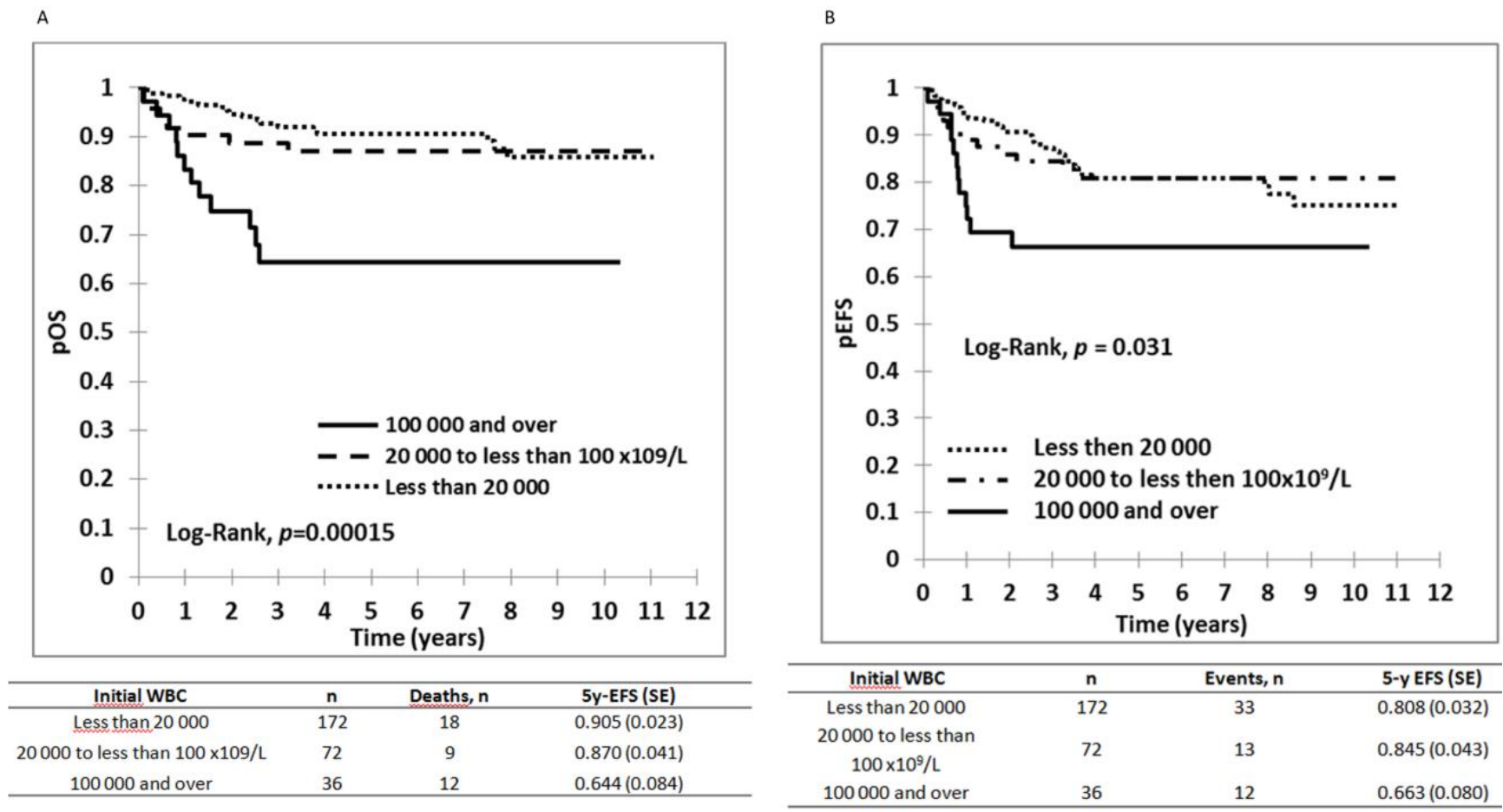

Figure S4. (A) Survival by initial white blood cell count. (B) Event free survival by initial white blood cell count.

A

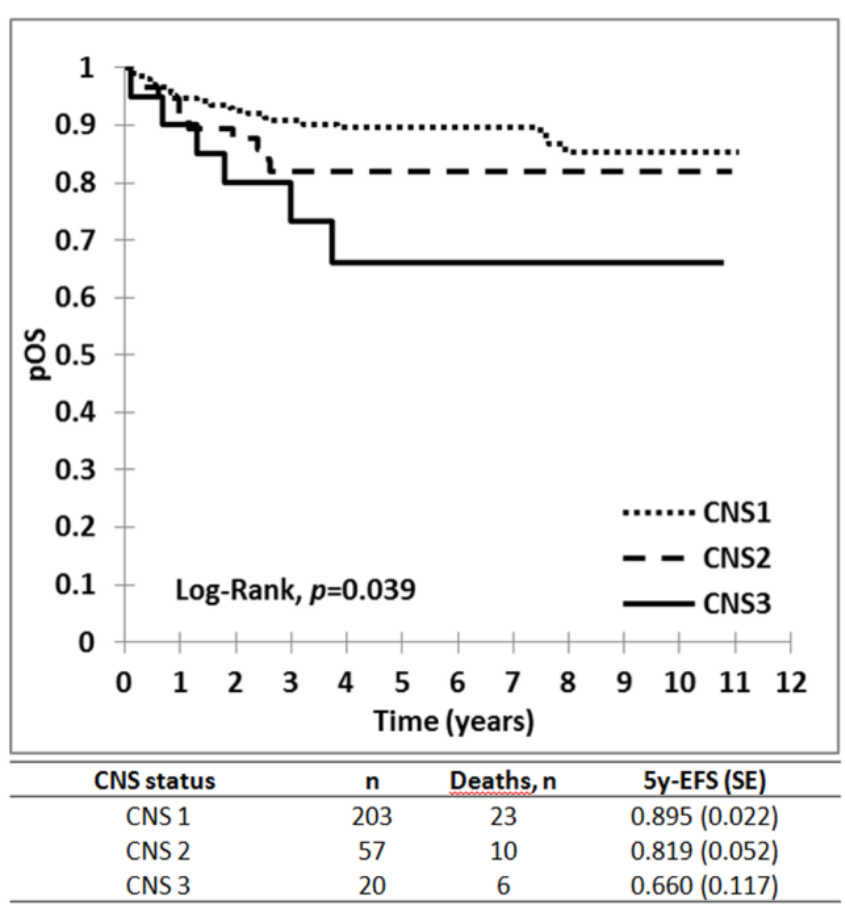

B

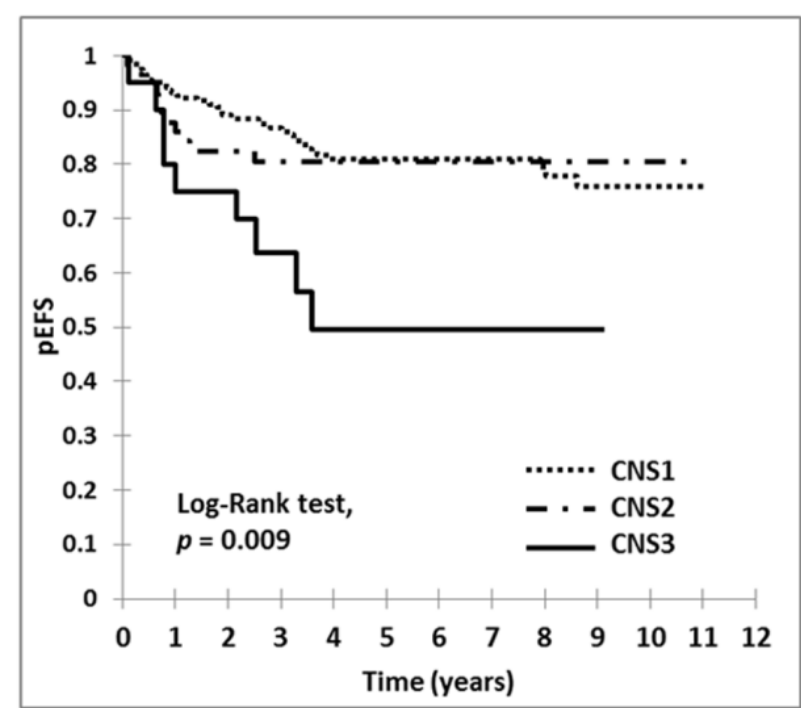

\begin{tabular}{cccc}
\hline CNS status & $\mathbf{n}$ & Events, $\mathbf{n}$ & 5-y EFS (SE) \\
\hline CNS1 & 203 & 38 & $0.810(0.029)$ \\
CNS2 & 57 & 11 & $0.805(0.053)$ \\
CNS3 & 20 & 9 & $0.495(0.124)$ \\
\hline
\end{tabular}

Figure S5. (A) Survival by CNS status. (B) Event free survival by CNS status. 
A

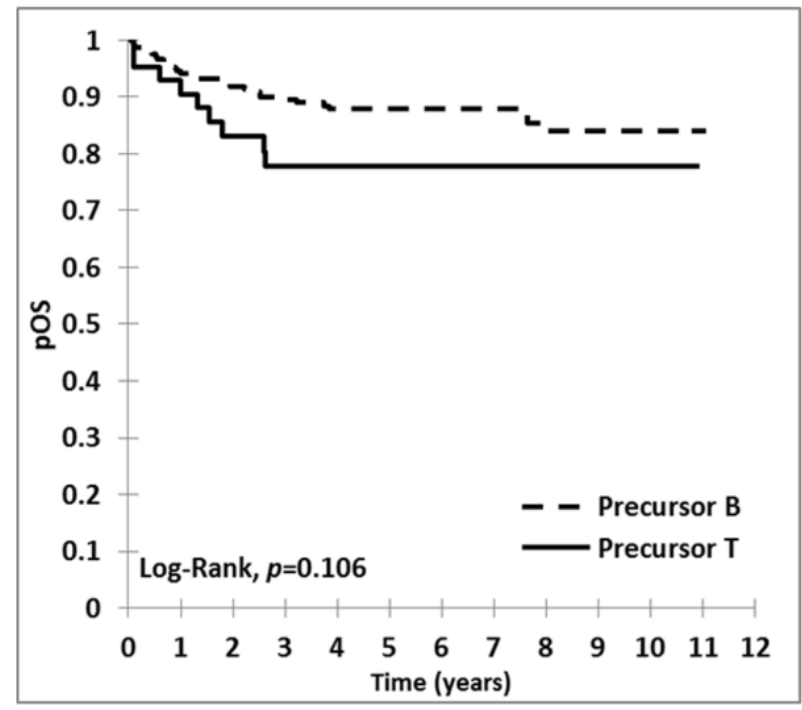

\begin{tabular}{cccc}
\hline Precursor & $\mathbf{n}$ & Deaths,n & 5y-pOS(SE) \\
\hline Precursor B & 238 & 30 & $0.879(0.022)$ \\
Precursor T & 42 & 9 & $0.777(0.066)$ \\
\hline
\end{tabular}

B

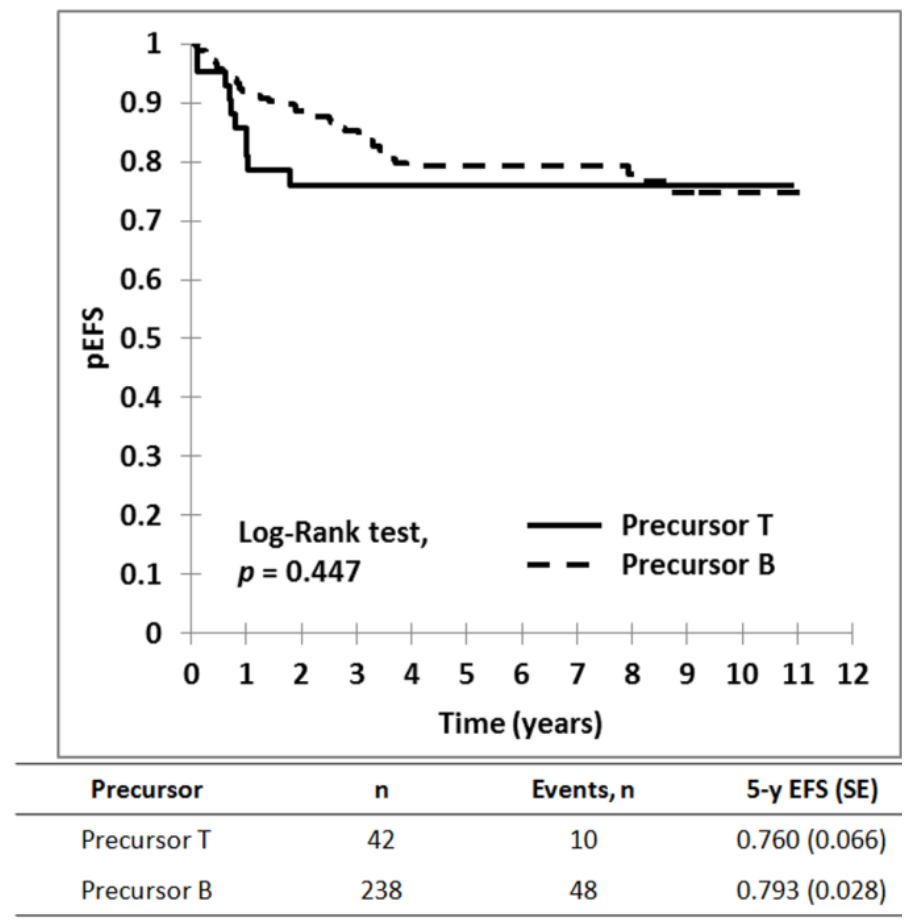

Figure S6. (A) Survival by imunophenotype. (B) Event free survival by immunophenotype.

A

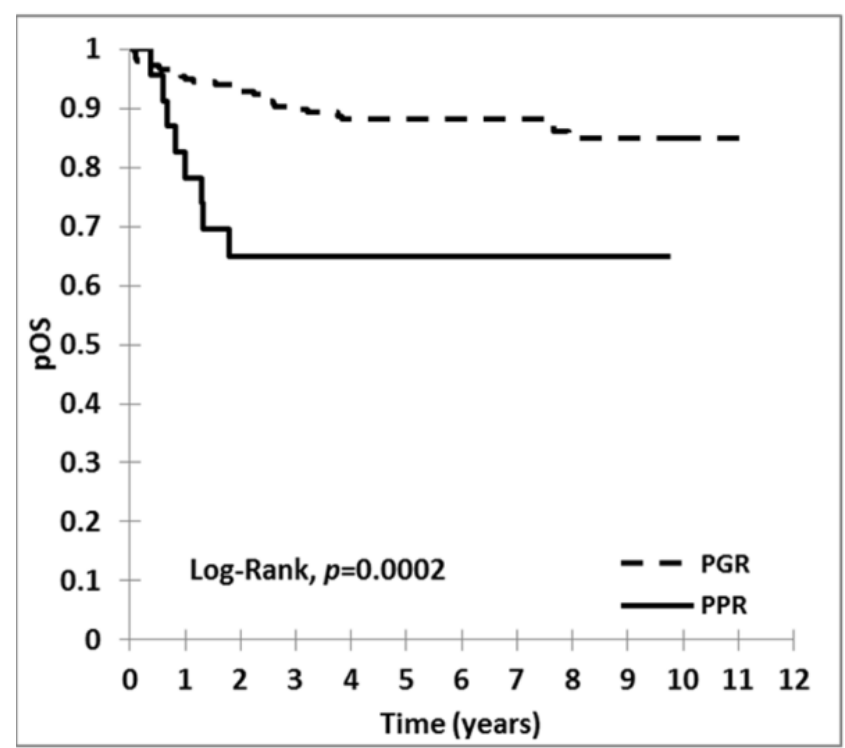

\begin{tabular}{cccc}
\hline Prednisone response & $\mathbf{n}$ & Deaths, $\mathbf{n}$ & 5y-OS(SE) \\
\hline Good & 257 & 31 & $0.883(0.021)$ \\
Poor & 23 & 8 & $0.649(0.100)$ \\
\hline
\end{tabular}

B

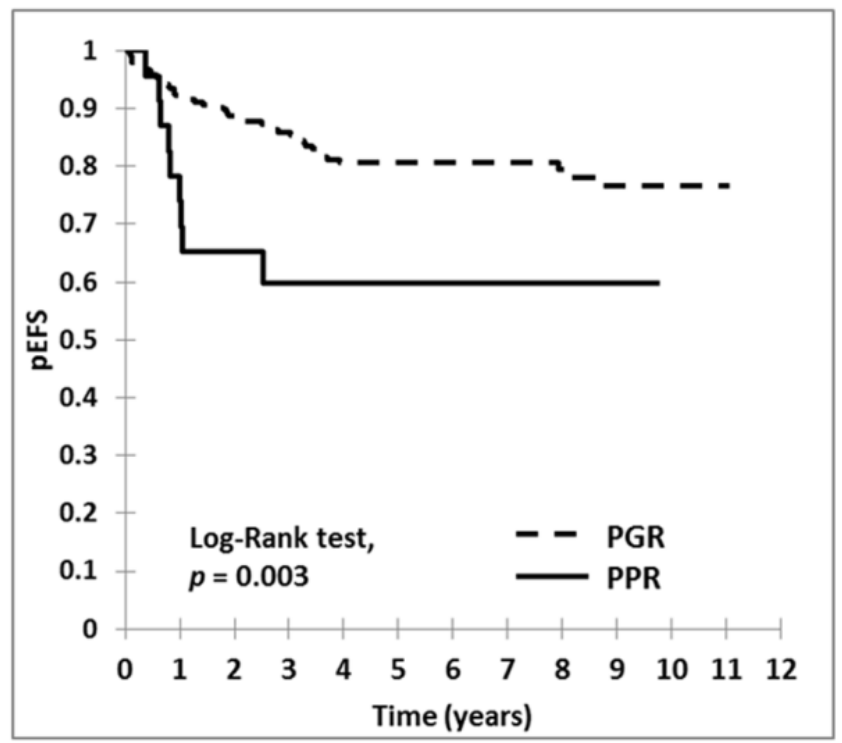

\begin{tabular}{cccc}
\hline Prednisone response & $\mathbf{n}$ & Events, $\mathbf{n}$ & 5-y EFS (SE) \\
\hline Good & 257 & 49 & $0.806(0.026)$ \\
Poor & 23 & 9 & $0.598(0.105)$ \\
\hline
\end{tabular}

Figure S7. (A) Survival by prednisone response on day 8. (B) Event free survival by prednisone response on day 8. 
A

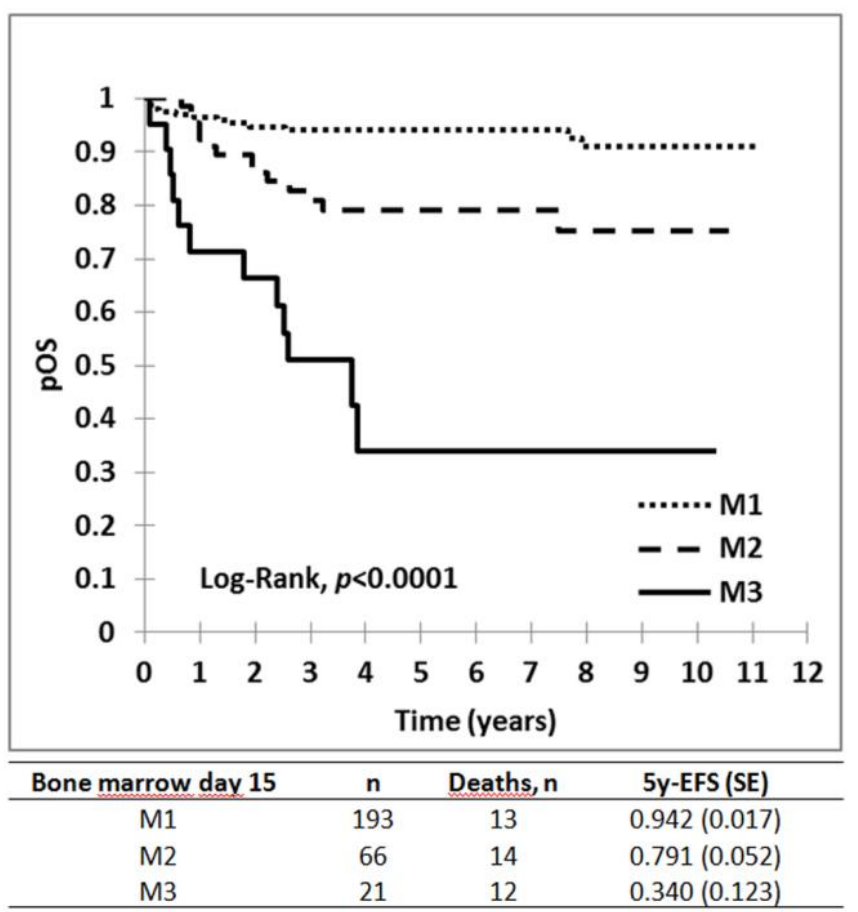

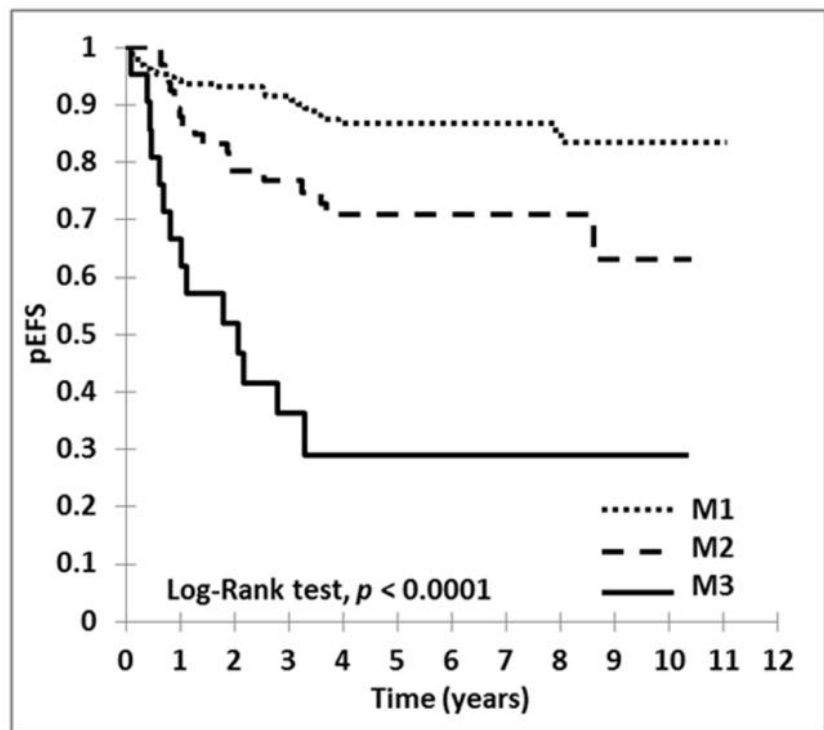

\begin{tabular}{cccc}
\hline Bone marrow day $\mathbf{1 5}$ & $\mathbf{n}$ & Events, $\mathbf{n}$ & 5y-EFS (SE) \\
\hline M1 & 193 & 25 & $0.868(0.026)$ \\
M2 & 66 & 19 & $0.709(0.059)$ \\
M3 & 21 & 14 & $0.291(0.108)$ \\
\hline
\end{tabular}

Figure S8. (A) Survival by response in bone marrow on day 15. (B) Event free survival by response in bone marrow on day 15.

A

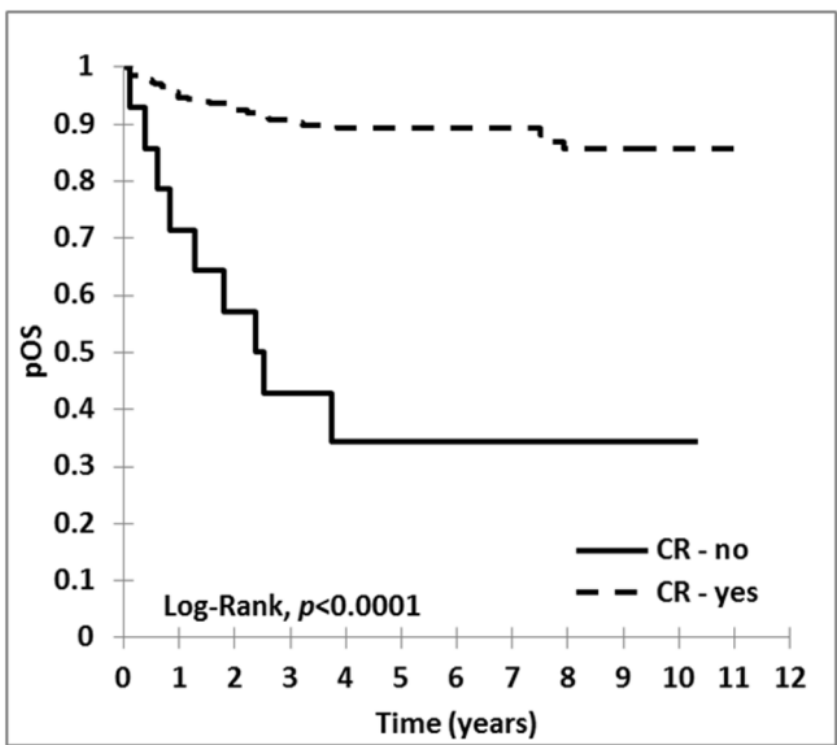

\begin{tabular}{cccc}
\hline Completed remission & $\mathbf{n}$ & Deaths, $\mathbf{n}$ & 5y-EFS (SE) \\
\hline No & 14 & 9 & $0.343(0.131)$ \\
Yes & 266 & 30 & $0.892(0.020)$ \\
\hline
\end{tabular}

B

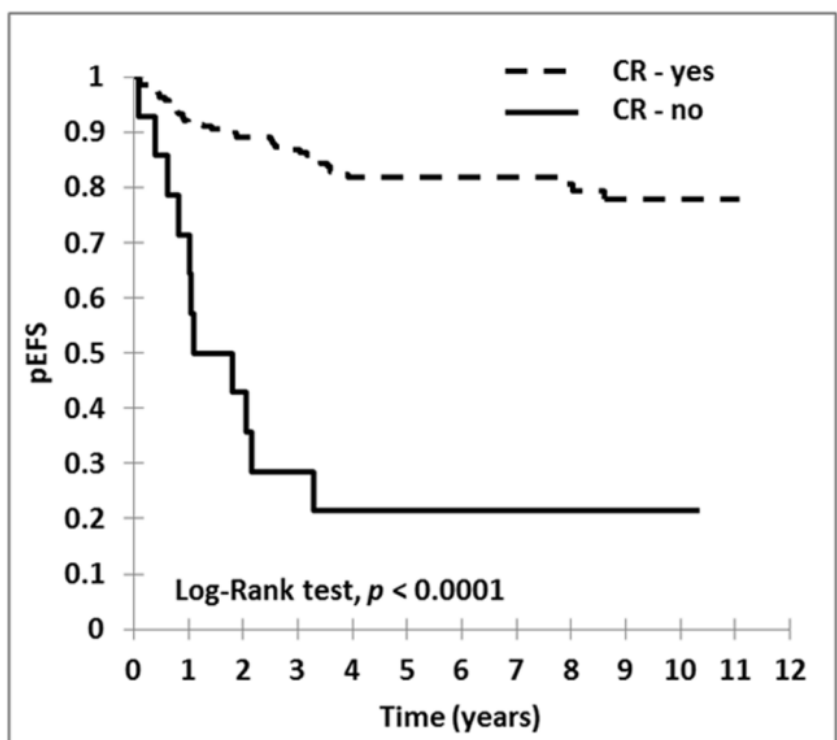

\begin{tabular}{cccc}
\hline Completed remission & $\mathbf{n}$ & Events, $\boldsymbol{n}$ & 5y-EFS (SE) \\
\hline Yes & 266 & 47 & $0.819(0.025)$ \\
No & 14 & 11 & $0.214(0.110)$ \\
\hline
\end{tabular}

Figure S9. (A) Survival by response in bone marrow on day 33. (B) Event free survival by response in bone marrow. on day 33. 